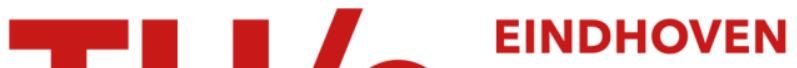 \\ UNIVERSITY OF \\ TECHNOLOGY
}

\section{Mechanism of cobalt-catalyzed CO hydrogenation}

\section{Citation for published version (APA):}

Chen, W., Pestman, R., Zijlstra, B., Filot, I. A. W., \& Hensen, E. J. M. (2017). Mechanism of cobalt-catalyzed CO hydrogenation: 1. Methanation. ACS Catalysis, 7(12), 8050-8060. https://doi.org/10.1021/acscatal.7b02757

DOI:

10.1021/acscatal.7b02757

Document status and date:

Published: 01/12/2017

\section{Document Version:}

Publisher's PDF, also known as Version of Record (includes final page, issue and volume numbers)

\section{Please check the document version of this publication:}

- A submitted manuscript is the version of the article upon submission and before peer-review. There can be important differences between the submitted version and the official published version of record. People interested in the research are advised to contact the author for the final version of the publication, or visit the $\mathrm{DOI}$ to the publisher's website.

- The final author version and the galley proof are versions of the publication after peer review.

- The final published version features the final layout of the paper including the volume, issue and page numbers.

Link to publication

\section{General rights}

Copyright and moral rights for the publications made accessible in the public portal are retained by the authors and/or other copyright owners and it is a condition of accessing publications that users recognise and abide by the legal requirements associated with these rights.

- Users may download and print one copy of any publication from the public portal for the purpose of private study or research.

- You may not further distribute the material or use it for any profit-making activity or commercial gain

- You may freely distribute the URL identifying the publication in the public portal.

If the publication is distributed under the terms of Article 25fa of the Dutch Copyright Act, indicated by the "Taverne" license above, please follow below link for the End User Agreement:

www.tue.nl/taverne

Take down policy

If you believe that this document breaches copyright please contact us at:

openaccess@tue.nl

providing details and we will investigate your claim. 


\title{
Mechanism of Cobalt-Catalyzed CO Hydrogenation: 1. Methanation
}

\author{
Wei Chen, Robert Pestman, Bart Zijlstra, Ivo A. W. Filot, ${ }^{\circledR}$ and Emiel J. M. Hensen*(i) \\ Inorganic Materials Chemistry, Schuit Institute of Catalysis, Department of Chemical Engineering and Chemistry, Eindhoven \\ University of Technology, P.O. Box 513, 5600 MB Eindhoven, The Netherlands
}

\section{Supporting Information}

ABSTRACT: The mechanism of $\mathrm{CO}$ hydrogenation to $\mathrm{CH}_{4}$ at $260{ }^{\circ} \mathrm{C}$ on a cobalt catalyst is investigated using steady-state isotopic transient kinetic analysis (SSITKA) and backward and forward chemical transient kinetic analysis (CTKA). The dependence of $\mathrm{CH}_{x}$ residence time is determined by ${ }^{12} \mathrm{CO} / \mathrm{H}_{2} \rightarrow$ ${ }^{13} \mathrm{CO} / \mathrm{H}_{2}$ SSITKA as a function of the $\mathrm{CO}$ and $\mathrm{H}_{2}$ partial pressure and shows that the $\mathrm{CH}_{4}$ formation rate is mainly controlled by $\mathrm{CH}_{x}$ hydrogenation rather than $\mathrm{CO}$ dissociation. Backward $\mathrm{CO} / \mathrm{H}_{2} \rightarrow \mathrm{H}_{2}$ CTKA emphasizes the importance of $\mathrm{H}$ coverage on the slow $\mathrm{CH}_{x}$ hydrogenation step. The $\mathrm{H}$ coverage strongly depends on the $\mathrm{CO}$ coverage, which is directly related to $\mathrm{CO}$ partial pressure. Combining SSITKA and backward CTKA allows determining that the amount of additional $\mathrm{CH}_{4}$ obtained during CTKA is nearly equal to the amount of $\mathrm{CO}$ adsorbed to the cobalt surface. Thus, under the given conditions overall barrier for $\mathrm{CO}$ hydrogenation to $\mathrm{CH}_{4}$ under methanation condition is
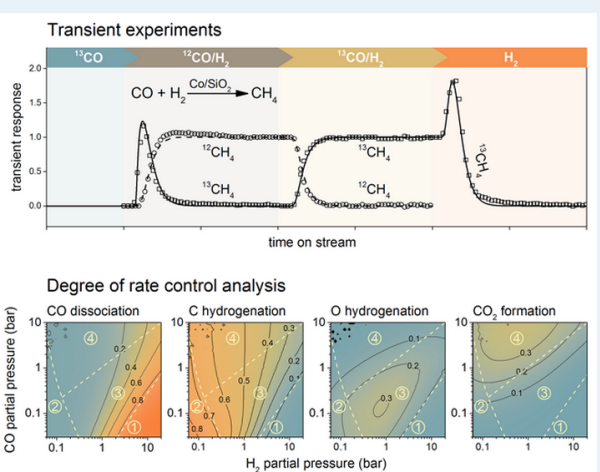
lower than the $\mathrm{CO}$ adsorption energy. Forward CTKA measurements reveal that $\mathrm{O}$ hydrogenation to $\mathrm{H}_{2} \mathrm{O}$ is also a relatively slow step compared to CO dissociation. The combined transient kinetic data are used to fit an explicit microkinetic model for the methanation reaction. The mechanism involving direct $\mathrm{CO}$ dissociation represents the data better than a mechanism in which $\mathrm{H}$ assisted $\mathrm{CO}$ dissociation is assumed. Microkinetics simulations based on the fitted parameters confirms that under methanation conditions the overall $\mathrm{CO}$ consumption rate is mainly controlled by $\mathrm{C}$ hydrogenation and to a smaller degree by $\mathrm{O}$ hydrogenation and $\mathrm{CO}$ dissociation. These simulations are also used to explore the influence of $\mathrm{CO}$ and $\mathrm{H}_{2}$ partial pressure on possible rate-controlling steps.

KEYWORDS: cobalt, methanation, mechanism, SSITKA, rate-limiting step

\section{INTRODUCTION}

Fischer-Tropsch synthesis is a heterogeneously catalyzed reaction whereby synthesis gas (a mixture of carbon monoxide and hydrogen) is converted into liquid fuels and chemicals. ${ }^{1-3}$ Known since the seminal works of Franz Fischer and Hans Tropsch in the 1920 s, $^{4,5}$ the Fischer-Tropsch (FT) reaction has led to large-scale industrial applications to upgrade carbonaceous feedstock such as coal and natural gas into more valuable liquid products. Supported cobalt is the preferred catalyst for the FT reaction due to its high activity, high chaingrowth probability, low water-gas shift activity, and moderate deactivation. ${ }^{6}$ A key challenge of FT technology in practice is to combine high yield of long-chain hydrocarbons with low methane selectivity. Even for methane, the simplest hydrocarbon product of the FT reaction, the exact reaction mechanism has not been resolved yet. Mechanisms proposed for the FT reaction are often based on postulated ratedetermining steps leading to Langmuir-Hinshelwood equations $^{7}$ or have been developed using empiric rate equations. ${ }^{8}$ Some of these models for the FT reaction are very sophisticated in their ability to describe important kinetic parameters such as $\mathrm{CO}$ consumption rate, ${ }^{9}$ chain-growth probability, ${ }^{10}$ and other aspects such as olefin readsorption and hydrogenation. ${ }^{11,12}$ Nevertheless, given the complexity of the FT reaction-the large number of involved reactants, products and reaction intermediates, and the uncertainty about the reaction mechanism-there is a great need to investigate this important reaction in more detail.

Detailed insight into reaction mechanism, specifically into the way particular elementary reaction steps control reaction rate and selectivity, can be obtained by transient experiments. Transient techniques involving isotopes were developed by Happel, ${ }^{13-15}$ Bennett $^{16,17}$ and Biloen. ${ }^{18-20}$ Steady-state isotopic transient kinetic analysis (SSITKA) allows extracting kinetic information under steady-state conditions. The unique feature of SSITKA is that the chemical composition of the surface is not changed by the abrupt replacement of one reactant by its isotope. ${ }^{21}$ Using this technique surface coverages and kinetic rate constants of rate-controlling steps can be determined unperturbed by changes in surface coverage. This sets SSITKA apart from chemical transient kinetic analysis techniques. Reviews of the SSITKA methodology are given by Shannon and Goodwin ${ }^{22}$ and Ledesma et al. ${ }^{23}$

Received: August 14, 2017

Revised: September 24, 2017

Published: October 16, 2017 
SSITKA has already been used before to investigate the mechanism of FT catalysts. ${ }^{24-27}$ The majority of these studies focused on methanation, ${ }^{28-34}$ because the involved molecules are small enough to be traced online by mass spectrometry and also because the reaction network leading to methane can be formulated robustly in terms of elementary reaction steps. Regarding cobalt-catalyzed FT synthesis, it is usually assumed that $\mathrm{CO}$ dissociation is the rate-determining step based on the observation that the reaction order with respect to $\mathrm{CO}$ is negative. Matsumoto ${ }^{17}$ and Biloen ${ }^{18}$ made early attempts to understand the FT mechanism by transient kinetics. Another important work by Winslow and Bell combined isotopic transient kinetic analysis with in situ infrared spectroscopy to investigate the FT mechanism for supported ruthenium. ${ }^{35}$ Winslow and Bell showed the existence of two different carbon species, one being a reactive surface intermediate and the other one involved in deactivation. These two pools of carbidic carbon have also been observed by others such as Happel et al. for nickel ${ }^{15}$ and van Dijk et al. for cobalt ${ }^{36}$ albeit that, different from the work of Winslow and Bell, all of the species could be hydrogenated to methane. Van Dijk et al. reported that $\mathrm{C}$ hydrogenation is the slow step in the mechanism of $\mathrm{CO}$ hydrogenation to methane by supported cobalt. ${ }^{24,36}$ More recently, Yang et al. attributed the $\mathrm{H}_{2}$ partial pressure dependence of the methanation reaction to the $\mathrm{H}$-assisted nature of $\mathrm{CO}$ dissociation. ${ }^{30}$ Den Breejen et al. ${ }^{31}$ and Yang et al. $^{32}$ interpreted the cobalt particle size effect in terms of strongly bonded $\mathrm{C}$ and $\mathrm{O}$ atoms on small cobalt particles on the basis of SSITKA data. SSITKA investigations of promoter effects of rhenium and zinc on cobalt were reported by Yang et al. $^{33}$ and Enger et al., ${ }^{34}$ respectively. Recent progresses in understanding the FT mechanism by SSITKA has been reviewed by Qi et al. ${ }^{37}$

An important related aspect of the FT mechanism in this regard is the mode of $\mathrm{CO}$ dissociation. With the advent of density functional theory, the sensitivity of dissociation of molecules like $\mathrm{CO},{ }^{38-42} \mathrm{NO},{ }^{43}$ and $\mathrm{N}_{2}{ }^{44,45}$ to the topology of metal surfaces that enclose catalytic nanoparticles has been extensively investigated. Accordingly, it has been realized that direct CO dissociation is highly likely on step-edge sites, ${ }^{39-42}$ because the terrace sites, which dominate the surface of sufficiently large nanoparticles, ${ }^{46,47}$ are not reactive enough. Another view is that $\mathrm{CO}$ activation takes place on terrace sites through an $\mathrm{H}$-assisted mechanism. ${ }^{30,48-52}$ Although it is difficult to disprove an $\mathrm{H}$-assisted $\mathrm{CO}$ dissociation mechanism on a surface that contains adsorbed $\mathrm{CO}$ and $\mathrm{H}$, we have recently demonstrated by isotopic exchange of a ${ }^{12} \mathrm{C}^{16} \mathrm{O} /{ }^{13} \mathrm{C}^{18} \mathrm{O}$ mixture that $\mathrm{CO}$ dissociation is fast and reversible on an empty cobalt surface. ${ }^{53}$

The purpose of the present work is to provide new mechanistic insight into the $\mathrm{CO}$ methanation reaction based on direct $\mathrm{CO}$ dissociation employing transient kinetic techniques. We discuss an interpretation of the $\mathrm{H}_{2}$ pressure dependence of the methanation reaction that is different from $\mathrm{H}$-assisted $\mathrm{CO}$ dissociation. We employ two different types of transients, a SSITKA switch involving a change in the isotopic labeling of the feed, $\left({ }^{12} \mathrm{CO} / \mathrm{H}_{2} / \mathrm{Ar} \rightarrow{ }^{13} \mathrm{CO} / \mathrm{H}_{2} / \mathrm{Ne}\right)$, and forward and backward CTKA transients involving $\mathrm{Ne} \rightarrow \mathrm{CO} /$ $\mathrm{H}_{2}, \mathrm{Ne} / \mathrm{H}_{2} \rightarrow \mathrm{CO} / \mathrm{H}_{2}$ and $\mathrm{CO} / \mathrm{H}_{2} \rightarrow \mathrm{Ne} / \mathrm{H}_{2}$ switches. The coverage dependence of the kinetic parameters extracted from these transient measurements was evaluated by varying the $\mathrm{CO}$ and $\mathrm{H}_{2}$ pressures. The obtained steady-state and transient data are modeled using the two $\mathrm{CO}$ dissociation mechanisms. The direct $\mathrm{CO}$ dissociation model that describes the data better is then used to carry out microkinetics simulations to identify the elementary reaction steps that control the $\mathrm{CO}$ consumption rate. An important corollary of this study will be that $\mathrm{CO}$ dissociation is not the rate-controlling step under methanation conditions at $260{ }^{\circ} \mathrm{C}$. Instead, hydrogenation of $\mathrm{O}$ and especially of $\mathrm{C}$ atoms deriving from $\mathrm{CO}$ dissociation are identified as the slow steps. The consequences of applying different conditions $\left(\mathrm{H}_{2} / \mathrm{CO}\right.$ ratios and partial pressures) on surface composition and major rate-controlling steps will be discussed.

\section{EXPERIMENTAL SECTION}

Preparation and Basic Characterization. A silicasupported Co catalyst promoted by $\mathrm{Pt}$ was prepared by incipient wetness impregnation of $\mathrm{SiO}_{2}$ (Shell, sieve fraction $120-250 \mu \mathrm{m}, 136 \mathrm{~m}^{2} / \mathrm{g}$ determined by BET) with an aqueous solution of $\mathrm{Co}\left(\mathrm{NO}_{3}\right)_{2} \cdot 6 \mathrm{H}_{2} \mathrm{O}$ (Merck, 99.99\%) and $\mathrm{Pt}\left(\mathrm{NH}_{3}\right)_{4}$. $\left(\mathrm{NO}_{3}\right)_{2}$ (Alfa Aesar, 99.995\%). Pt was added as a reduction promoter. The impregnated silica was dried at $110{ }^{\circ} \mathrm{C}$ for $12 \mathrm{~h}$ and then calcined at $350{ }^{\circ} \mathrm{C}$ in static air for $2 \mathrm{~h}$ after heating to this temperature at a rate of $1^{\circ} \mathrm{C} \mathrm{min}{ }^{-1}$. The catalyst contained 17.1 wt \% Co and 0.04 wt \% Pt as determined by ICP-OES analysis (Spectroblue, AMETEK, Inc.). Co dispersion was measured by $\mathrm{H}_{2}$-chemisorption (ASAP 2010, Micromeritics), which was carried out at $110{ }^{\circ} \mathrm{C}$ after reduction at $450{ }^{\circ} \mathrm{C}$ (heating rate $1{ }^{\circ} \mathrm{C} \mathrm{min}^{-1}$ ) for $6 \mathrm{~h}$ and evacuation at $470{ }^{\circ} \mathrm{C}$ for $3 \mathrm{~h}$. Taking into account the degree of reduction as measured by TPR (ASAP 2920 II, Micromeritics), the particle size determined by extrapolating the straight-line portion of the adsorption isotherm to zero pressure was $19 \mathrm{~nm}$. From TEM imaging (FEI Tecnai 20, LaB6, $200 \mathrm{kV}$ ), a volume-averaged particle size ${ }^{54,55}$ of $15 \mathrm{~nm}$ was determined. The Co crystallite size determined by in situ XRD (D/max-2600, Rigaku) of the reduced catalyst by use of the Scherrer equation was $14.7 \mathrm{~nm}$.

Catalytic Activity Measurements. Catalytic activity measurements were performed in a setup that is capable of transient experiments. Two identical gas-feeding units were connected to a four-way valve, which allows rapidly switching between the two feed flows. Great care was taken to keep flow perturbations minimal during switching. This was done by imposing similar pressure drop over the system between the two flow lines and the use of properly regulated mass flow controllers. A low dead-volume stainless-steel tubular reactor of $5 \mathrm{~mm}$ inner diameter and $80 \mathrm{~mm}$ bed length was used. The catalytic activity in steady state was determined by online gas chromatography (VARIAN CP-3800 equipped with TCD and FID).

Typically, $20 \mathrm{mg}$ of sample diluted with $\mathrm{SiC}$ was loaded in the stainless-steel reactor. Prior to reaction, the sample was in situ reduced in a diluted $\mathrm{H}_{2}$ flow $\left(10 \% \mathrm{H}_{2}\right.$ in $\mathrm{Ar}, 50 \mathrm{~mL} \mathrm{~min}{ }^{-1}$ in total) at $450{ }^{\circ} \mathrm{C}$ using a heating rate of $2{ }^{\circ} \mathrm{C} \mathrm{min}-1$ and atmospheric pressure for $16 \mathrm{~h}$. Subsequently, the sample was cooled to $260{ }^{\circ} \mathrm{C}$ in an Ar flow and the pressure was increased to 1.5 bar. Thereafter, the feed was switched to a flow containing a mixture of ${ }^{12} \mathrm{CO}, \mathrm{H}_{2}$, and $\mathrm{Ar}$ for $16 \mathrm{~h}$ to obtain steady-state conversion of the synthesis gas feed.

Transient Kinetic Experiments. Three types of transient kinetic analyses were performed, i.e., forward and backward chemical transient kinetic analysis (CTKA) $)^{21,56-58}$ involving a change in the chemical composition of the gas phase (forward transient involving $\mathrm{Ne} \rightarrow \mathrm{CO} / \mathrm{H}_{2}$ or $\mathrm{Ne} / \mathrm{H}_{2} \rightarrow \mathrm{CO} / \mathrm{H}_{2}$; backward transient involving $\mathrm{CO} / \mathrm{H}_{2} \rightarrow \mathrm{Ne} / \mathrm{H}_{2}$ ) and a steady- 

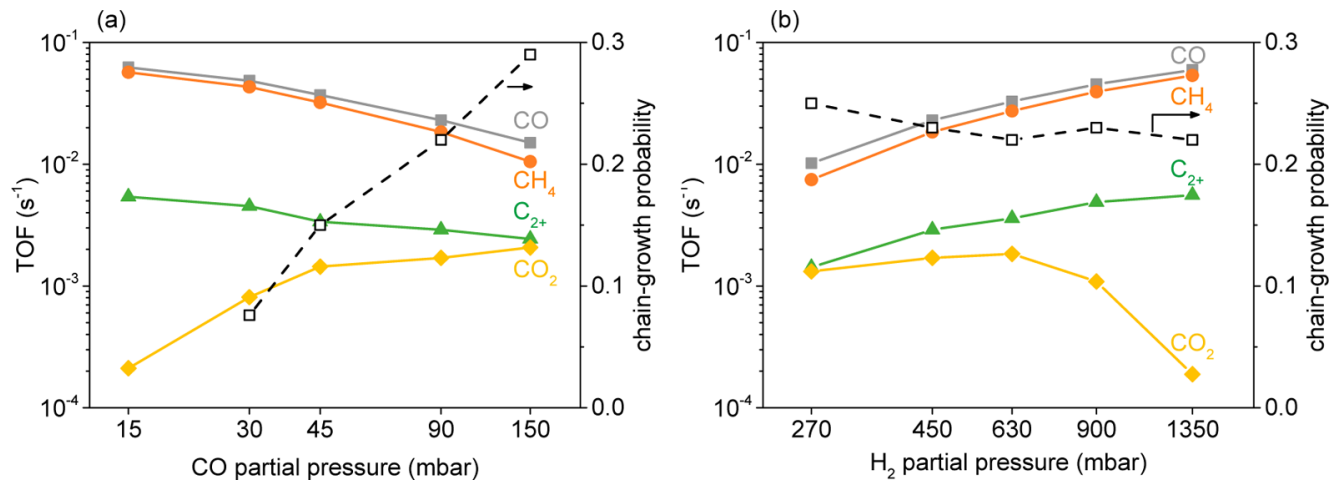

Figure 1. Turnover frequencies of $\mathrm{CO}$ consumption (squares), $\mathrm{CH}_{4}$ formation (circles), $\mathrm{C}_{2+}$ formation (triangles), $\mathrm{CO}_{2}$ formation (diamonds) and chain growth probability (open squares) as a function of $\mathrm{CO}$ partial pressure (a) and $\mathrm{H}_{2}$ partial pressure (b). Conditions: $T=260{ }^{\circ} \mathrm{C}, p_{\mathrm{H}_{2}}=450$ mbar at varying $\mathrm{CO}$ partial pressure, $p_{\mathrm{CO}}=90$ mbar at varying $\mathrm{H}_{2}$ partial pressure.

state isotopic transient kinetic analysis (SSITKA) involving a change in the isotopic labeling of the feed $\left({ }^{12} \mathrm{CO} / \mathrm{H}_{2} / \mathrm{Ar} \rightarrow\right.$ $\left.{ }^{13} \mathrm{CO} / \mathrm{H}_{2} / \mathrm{Ne}\right)$. In CTKA experiments, the $\mathrm{Ne}$ flow was used as balance to keep the total flow rate unchanged after switch. In SSITKA, the Ne was used as tracer to determine the gas-phase hold-up of the reactor. In all the experiments, an additional Ar flow was used as balance to keep $\mathrm{H}_{2}$ partial pressure and total flow rate at $50 \mathrm{~mL} \mathrm{~min}{ }^{-1}$ when the $\mathrm{CO} / \mathrm{H}_{2}$ ratio was varied. The concentrations of $\mathrm{H}_{2}(m / z=2), \mathrm{H}_{2} \mathrm{O}(m / z=18),{ }^{12} \mathrm{CO}$ $(m / z=28),{ }^{13} \mathrm{CO}(m / z=29),{ }^{12} \mathrm{CH}_{4}(m / z=15),{ }^{13} \mathrm{CH}_{4}(m / z$ $=17), \mathrm{Ne}(m / z=22)$, and $\operatorname{Ar}(m / z=40)$ were monitored by an online quadrupole mass spectrometer (GeneSys).

The $\mathrm{CO}$ residence time $(\tau)$ was calculated via the area under the normalized transient curves $N_{\mathrm{CO}}(\mathrm{t})$, and corrected for the gas phase hold-up with the use of the $\mathrm{Ne}$ inert tracer.

$$
\tau_{\mathrm{CO}}=\int_{0}^{\infty}\left(N_{\mathrm{CO}}-N_{\mathrm{Ne}}\right) \mathrm{d} t
$$

The $\mathrm{CH}_{x}$ (surface intermediates leading to methane) residence time was first determined in a similar way as $\mathrm{CO}$, but corrected for the chromatographic effect of $\mathrm{CO}$ by subtracting half of the $\mathrm{CO}$ residence time. ${ }^{18}$

$$
\tau_{\mathrm{CH}_{\mathrm{x}}}=\int_{0}^{\infty}\left(N_{\mathrm{CH}_{4}}-N_{\mathrm{Ne}}\right) \mathrm{d} t-\frac{1}{2} \tau_{\mathrm{CO}}
$$

The number of reversibly adsorbed $\mathrm{CO}$ and adsorbed $\mathrm{CH}_{x}$ species can be determined from the residence time and exit flow of the corresponding species. Taking into account the dispersion (the value derived from $\mathrm{H}_{2}$-chemisorption), the surface coverage of $\mathrm{CO}$ and $\mathrm{CH}_{x}$ can be calculated.

$$
\begin{aligned}
& \theta_{\mathrm{CO}}=\tau_{\mathrm{CO}} \frac{F_{\mathrm{CO}}\left(1-X_{\mathrm{CO}}\right)}{A_{\mathrm{Co}}} \\
& \theta_{\mathrm{CH}_{\mathrm{x}}}=\tau_{\mathrm{CH}_{\mathrm{x}}} \frac{F_{\mathrm{CO}} X_{\mathrm{CO}_{\mathrm{CH}_{4}}} S_{\mathrm{Co}}}{A_{\mathrm{C}}}
\end{aligned}
$$

where $F_{\mathrm{CO}}$ refers to the $\mathrm{CO}$ feed rate, $A_{\mathrm{Co}}$ is the number of accessible Co surface atoms determined by $\mathrm{H}_{2}$-chemisorption, and $X_{\mathrm{CO}}$ and $\mathrm{S}_{\mathrm{CH}_{4}}$ are $\mathrm{CO}$ conversion and $\mathrm{CH}_{4}$ selectivity, respectively.

\section{RESULTS AND DISCUSSION}

Steady-State Kinetic Measurements. We first investigated the steady-state kinetics of the $\mathrm{Co} / \mathrm{SiO}_{2}$ catalyst at a temperature of $260{ }^{\circ} \mathrm{C}$ in order to determine reaction orders with respect to $\mathrm{CO}$ and $\mathrm{H}_{2}$. The dependences of the reaction rates (expressed as turnover frequency, TOF) of $\mathrm{CO}$ consumption, $\mathrm{CH}_{4}$ formation, $\mathrm{C}_{2+}$ formation, $\mathrm{CO}_{2}$ formation and the chain-growth probability on $\mathrm{CO}$ and $\mathrm{H}_{2}$ partial pressures are presented in Figure 1. The $\mathrm{CO}$ and $\mathrm{H}_{2}$ partial pressures were varied between 15 and 150 mbar and 270-1350 mbar, respectively. At $260{ }^{\circ} \mathrm{C}$, the main product of $\mathrm{CO}$ hydrogenation is $\mathrm{CH}_{4}$. Under such methanation conditions, the chain-growth probability is low. Apparent reaction orders with respect to $\mathrm{CO}$ and $\mathrm{H}_{2}$ are listed in Table 1 . In line with

Table 1. Apparent Reaction Orders with Respect to CO and $\mathrm{H}_{2}$ Based on CO Consumption Rate and Formation Rates of $\mathrm{CH}_{4}, \mathrm{C}_{2+}$ and $\mathrm{CO}_{2}$ Determined at $260^{\circ} \mathrm{C}^{a}$

\begin{tabular}{ccc} 
& \multicolumn{2}{c}{ reaction order } \\
\cline { 2 - 3 } rate based on & $\mathrm{CO}^{b}$ & $\mathrm{H}_{2}{ }^{c}$ \\
$\mathrm{CO}$ & -0.61 & 1.08 \\
$\mathrm{CH}_{4}$ & -0.72 & 1.20 \\
$\mathrm{C}_{2+}{ }^{2}$ & -0.32 & 0.45 \\
$\mathrm{CO}_{2}$ & 0.95 & -1.09
\end{tabular}

${ }^{a}$ Data were acquired after $16 \mathrm{~h}$ time on stream. ${ }^{b} p_{\mathrm{H}_{2}}=450 \mathrm{mbar}, p_{\mathrm{CO}}$ varied from 15 mbar to 150 mbar. ${ }^{c} p_{\mathrm{CO}}=90$ mbar, $p_{\mathrm{H}_{2}}$ varied from 270 mbar to 1350 mbar. ${ }^{d} \mathrm{C}_{2+}$ refers to all hydrocarbons containing two or more carbon atoms.

literature, ${ }^{30}$ the methanation rate decreases with increasing $\mathrm{CO}$ partial pressure, while the reverse holds true for the dependence on $\mathrm{H}_{2}$ partial pressure. The negative reaction order with respect to $\mathrm{CO}$ can be interpreted in terms of a decrease in free sites needed for $\mathrm{CO}$ dissociation. ${ }^{59}$ An alternative interpretation is a lack of $\mathrm{H}$ atoms needed for methanation. The reaction order with respect to $\mathrm{H}_{2}$ is slightly higher than unity, implying that hydrogenation of $\mathrm{CO}$ or hydrogenation of $\mathrm{C}$ or $\mathrm{O}$ atoms are rate-controlling steps. We observe that the reaction order with respect to $\mathrm{H}_{2}$ based on the $\mathrm{CH}_{4}$ formation rate is higher than the corresponding reaction order based on the formation rate of $\mathrm{C}_{2+}$-hydrocarbon products. This suggests that the $\mathrm{H}_{2}$ partial pressure dependence at least in part originates from the ratecontrolling nature of hydrogenation of $\mathrm{C}$ atoms, as less $\mathrm{C}$ hydrogenation steps for each $\mathrm{C}$ atom are involved in the formation of $\mathrm{C}_{2+}$-hydrocarbon products than in the formation of $\mathrm{CH}_{4}$. The rate of $\mathrm{CO}_{2}$ formation increases with $\mathrm{CO}$ partial pressure and decreases with $\mathrm{H}_{2}$ partial pressure. These 

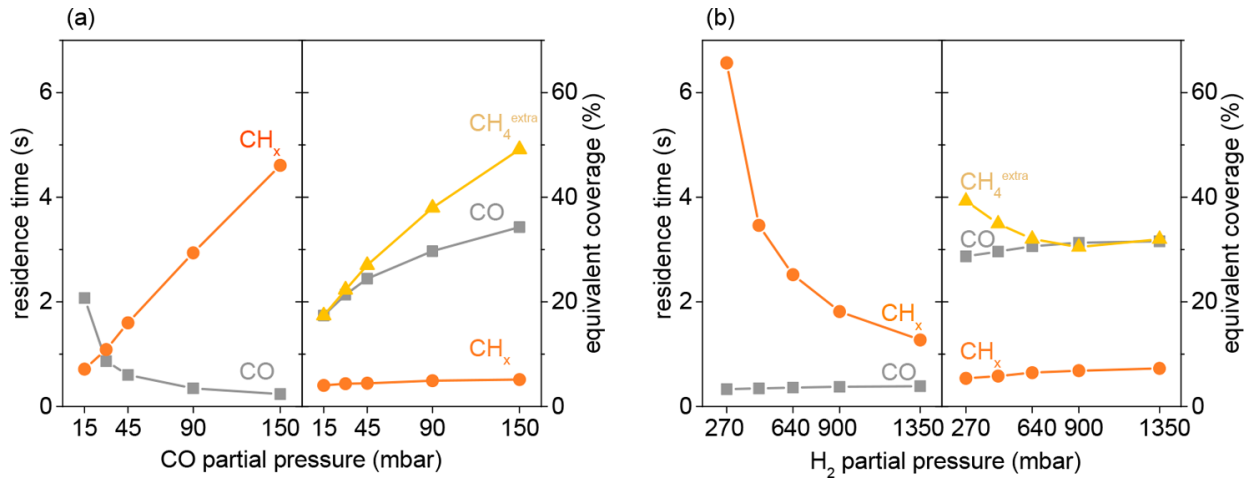

Figure 2. Residence times (left panels) and equivalent coverages (right panels) of $\mathrm{CO}$ (squares), $\mathrm{CH}_{x}$ (circles), and extra- $\mathrm{CH}_{4}$ (triangles, defined in Figure 4.) as a function of $\mathrm{CO}$ partial pressure (a) and $\mathrm{H}_{2}$ partial pressure (b). Conditions: $T=260{ }^{\circ} \mathrm{C}, p_{\mathrm{H}_{2}}=450$ mbar at varying $\mathrm{CO}$ partial pressure, $p_{\mathrm{CO}}=90$ mbar at varying $\mathrm{H}_{2}$ partial pressure.

dependencies point to competition of $\mathrm{O}$ removal pathways via $\mathrm{CO}_{2}$ and $\mathrm{H}_{2} \mathrm{O}$. Although $\mathrm{CO}_{2}$ formation cannot be neglected especially at high $\mathrm{CO}$ partial pressure, the dominant $\mathrm{O}$ removal pathway is via $\mathrm{H}_{2} \mathrm{O}$. It is interesting to note that the chaingrowth probability only changes significantly with $\mathrm{CO}$ partial pressure, implying a strong influence of surface coverage on the chain-growth process. This observation will be discussed in more detailed in a companion paper that focuses on similar measurements under FT conditions at a temperature of $220^{\circ} \mathrm{C}$.

Steady-State Isotopic Transient Kinetic Analysis (SSITKA). After attaining steady state in a ${ }^{12} \mathrm{CO} / \mathrm{H}_{2}$ mixture, the catalyst was subjected to a SSITKA switch from ${ }^{12} \mathrm{CO} / \mathrm{H}_{2}$ $\rightarrow{ }^{13} \mathrm{CO} / \mathrm{H}_{2}$ in order to determine residence times $(\tau)$ of $\mathrm{CO}$ and $\mathrm{CH}_{x}$ (intermediates leading to $\mathrm{CH}_{4}$ ) by use of eqs 1 and 2 . Long residence time indicates low activity, and vice versa. Together with the site-normalized rates, $\mathrm{CO}$ and $\mathrm{CH}_{x}$ coverages can then be obtained by use of eqs 3 and 4 . These residence times and coverages are plotted as a function of the $\mathrm{CO}$ and $\mathrm{H}_{2}$ partial pressure in Figure 2. In good agreement with other studies, ${ }^{30}$ a higher $\mathrm{CO}$ partial pressure leads to a longer residence time of $\mathrm{CH}_{x}$. The reverse holds for changes in the $\mathrm{H}_{2}$ partial pressure. As widely assumed in literature, $\mathrm{CH}_{4}$ formation rate is a pseudo-first-order process with respect to the coverage of $\mathrm{CH}_{x}\left(\theta_{\mathrm{CH}_{x}}\right)$, $22,28-34$

$$
r_{\mathrm{CH}_{4}}=k^{\prime} \mathrm{CH}_{x} \theta_{\mathrm{CH}_{x}}
$$

where $k^{\prime}$ is a pseudo-first-order rate constant and, together with eq 4 , we can state that

$$
k^{\prime}{ }_{\mathrm{CH}_{x}}=\frac{1}{\tau_{\mathrm{CH}_{x}}}
$$

However, the pseudo-first-order assumption is not valid as the residence time also depends on the reactant partial pressure. Accordingly, we employed a more detailed analysis of the SSITKA results in which we assume that either $\mathrm{C}$ hydrogenation or $\mathrm{CO}$ dissociation is limiting the rate of $\mathrm{CH}_{4}$ formation. The first assumption leads to decoupling of the pseudo-first-order rate constant via

$$
r_{\mathrm{CH}_{4}}=k^{\prime} \theta_{\mathrm{CH}_{x}}=k_{\mathrm{CH}_{x}} \theta_{\mathrm{H}} \theta_{\mathrm{CH}_{x}}
$$

where $k_{\mathrm{CH}_{x}}$ is the rate constant of hydrogenation and $\theta_{\mathrm{H}}$ the $\mathrm{H}$ coverage. Therefore

$$
k_{\mathrm{CH}_{x}} \theta_{\mathrm{H}}=\frac{1}{\tau_{\mathrm{CH}_{\mathrm{x}}}}
$$

It should be noted that, at constant $\mathrm{H}_{2}$ partial pressure, an increase in $\mathrm{CO}$ partial pressure will considerably reduce the $\mathrm{H}$ coverage, because the $\mathrm{CO}$ adsorbs much stronger than $\mathrm{H}_{2}{ }^{60,61}$ On the other hand, changing $\mathrm{H}_{2}$ partial pressure affects $\mathrm{CO}$ coverage less profoundly as is evident from Figure $2 \mathrm{~b}$. Therefore, the dependence of $\tau_{\mathrm{CHx}}$ on either $\mathrm{CO}$ partial pressure or $\mathrm{H}_{2}$ partial pressure should be largely due to a change in the $\mathrm{H}$ coverage, even though this cannot be exactly measured.

Alternatively, when $\mathrm{CO}$ dissociation is assumed to be ratelimiting, the rate can be approximated by

$$
r_{\mathrm{CH}_{4}}=k_{\mathrm{diss}} \theta_{\mathrm{v}} \theta_{\mathrm{CO}}
$$

where $k_{\text {diss }}$ is the rate constant of $\mathrm{CO}$ dissociation and $\theta_{\mathrm{v}}$ and $\theta_{\mathrm{CO}}$ the surface coverages of free sites and $\mathrm{CO}$, respectively. However, this assumption fails in interpreting the SSITKA observations as a function of $\mathrm{H}_{2}$ partial pressure. We observe that $\mathrm{CO}$ coverage changes only slightly with varying $\mathrm{H}_{2}$ partial pressure (Figure $2 \mathrm{~b}$ ). Considering the constant $\mathrm{CO}$ partial pressure, the amount of vacant sites is not expected to significantly change with increasing $\mathrm{H}_{2}$ partial pressure. Consequently, the product of slightly changed $\theta_{\mathrm{v}}$ and $\theta_{\mathrm{CO}}$ cannot explain the 7-fold-increase in $\mathrm{CH}_{4}$ formation rate with increasing $\mathrm{H}_{2}$ partial pressure from 270 mbar to $1350 \mathrm{mbar}$ (Figure 1).

We therefore conclude that $\mathrm{CH}_{4}$ formation under methanation conditions is most likely controlled by hydrogenation steps that involve $\mathrm{H}$ atoms rather than by a $\mathrm{CO}$ dissociation step that involves vacancies. We also emphasize that the surface coverage plays an important role in determining the rate-controlling steps. It is to be expected that the FT reaction will occur in a different regime as $\mathrm{CO}$ coverage will be higher at the typically used lower temperature. SSITKA results obtained at $260{ }^{\circ} \mathrm{C}$ (this study) show the coverage of $\mathrm{CO}$, the most abundant surface species, is typically no more than 0.3 , which is lower than the value obtained at FT condition in a companion paper (typically 0.4 at $220^{\circ} \mathrm{C}$ ) and in literature $\left(0.48^{30}\right.$ and $0.45^{31}$ at $210{ }^{\circ} \mathrm{C}$ ). We should take care here, as analysis based on SSITKA alone is not able to distinguish an $\mathrm{H}$-assisted $\mathrm{CO}$ dissociation mechanism from $\mathrm{C}$ hydrogenation as the ratedetermining step, because both depend on the $\mathrm{H}$ coverage. As outlined above, we have demonstrated that direct $\mathrm{CO}$ 

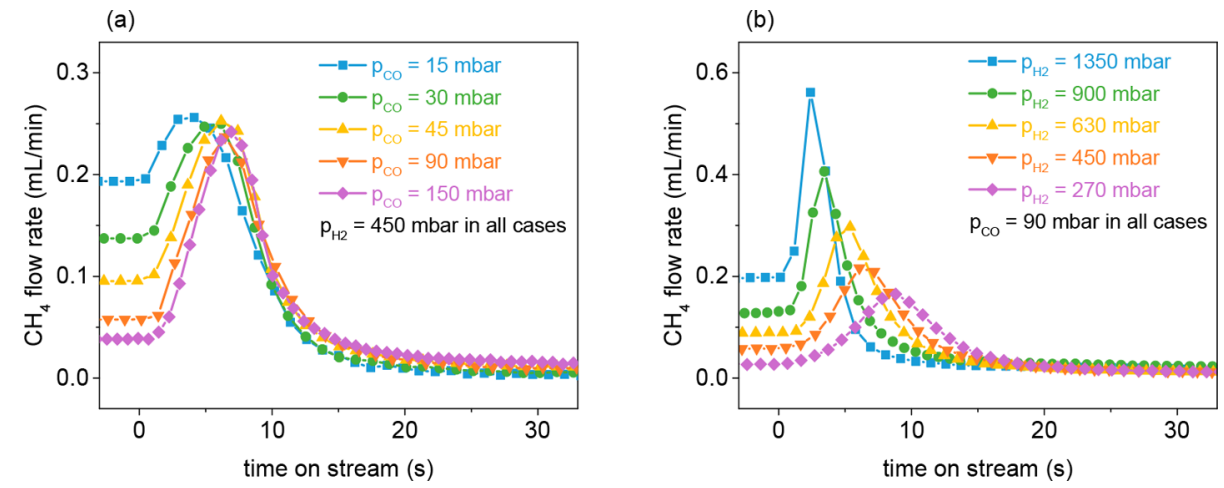

Figure 3. Backward transient at different $\mathrm{CO}$ partial pressures (a) and $\mathrm{H}_{2}$ partial pressures (b) after a switch from $\mathrm{CO} / \mathrm{H}_{2}$ to $\mathrm{H}_{2}$. Conditions: $T=$ $260{ }^{\circ} \mathrm{C}, p_{\mathrm{H}_{2}}=450$ mbar at varying $\mathrm{CO}$ partial pressure, $p_{\mathrm{CO}}=90 \mathrm{mbar}$ at varying $\mathrm{H}_{2}$ partial pressure.

dissociation on the same $\mathrm{Co} / \mathrm{SiO}_{2}$ catalyst is possible and can be correlated to a minority site at the surface. ${ }^{53}$ Therefore, the minor increase in $\mathrm{CO}$ coverage will significantly influence the reaction kinetics. This scenario will be discussed in a companion paper.

The SSITKA results reveal the strong influence of hydrogenation on the overall $\mathrm{CO}$ consumption rate. Both $\mathrm{C}$ and $\mathrm{O}$ hydrogenation should be considered. We therefore combine the results from SSITKA with those obtained in forward and backward CTKA and use them to fit a microkinetic model for $\mathrm{CO}$ hydrogenation to $\mathrm{CH}_{4}$. From this analysis, we can identify rate-controlling steps.

Backward Chemical Transient Kinetic Analysis. The backward CTKA experiment comprises a $\mathrm{CO} / \mathrm{H}_{2} \rightarrow \mathrm{Ne} / \mathrm{H}_{2}$ switch. Figure 3 shows that this switch leads to an increase in the $\mathrm{CH}_{4}$ formation rate followed by a decline toward zero. This phenomenon was first observed for a fused iron catalyst by Matsumoto and Bennett. ${ }^{17}$ Later, Cant et al. reported similar behavior for a $\mathrm{Ru}$ catalyst, ${ }^{62}$ attributing the increased methane formation rate to increased $\mathrm{H}$ coverage. Biloen also observed the same for a Ru catalyst and suggested that the initial increase in rate of methane formation is due to an increasing pseudofirst-order rate constant of methane formation. ${ }^{19}$ Kruse and coworkers discussed similar backward transient phenomena for a $\mathrm{Co} / \mathrm{MgO}$ catalyst. $^{56-58}$ They interpreted these CTKA data as evidence for the CO-insertion mechanism. More recently, Ralston et al. explained cobalt particle size-dependent CTKA data in terms of structure sensitivity, i.e., lack of $B_{5}-B$ sites for $\mathrm{CO}$ dissociation on small Co nanoparticles. ${ }^{63}$

The CTKA transients obtained at different $\mathrm{CO}$ and $\mathrm{H}_{2}$ partial pressures are shown in Figure 3. The maximum $\mathrm{CH}_{4}$ formation rates during the transient coincide with an optimum surface coverage ratio of vacancies, $\mathrm{CO}, \mathrm{CH}_{x}$, and $\mathrm{H}$, of which the latter two determine the $\mathrm{CH}_{4}$ formation rate. At constant $\mathrm{H}_{2}$ pressure, the $\mathrm{H}$ coverage will depend linearly on the fraction of free sites according to the adsorption equilibrium of $\mathrm{H}_{2}$. Accordingly, the optimum rate is achieved at optimum ratio of $\theta_{\mathrm{CH}_{x}}$ and $\theta_{\mathrm{H}}$. This ratio is independent of the initial steady-state coverage of $\mathrm{CO}$, but is reached later in time when the starting coverage is higher (Figure 3a). However, when the $\mathrm{CO}$ partial pressure is constant and the $\mathrm{H}_{2}$ partial pressure is varied, the $\mathrm{H}_{2}$ adsorption equilibrium will lead to increasing $\mathrm{H}$ coverage at higher $\mathrm{H}_{2}$ partial pressure. This will lead to higher and earlier maximum $\mathrm{CH}_{4}$ formation rate (Figure $3 \mathrm{~b}$ ). Evidently, the $\mathrm{CH}_{4}$ formation rate is highly dependent on the $\mathrm{H}$ coverage.
Here, we combine for the first time SSITKA with backward CTKA in order to construct Figure 4. In this figure, we

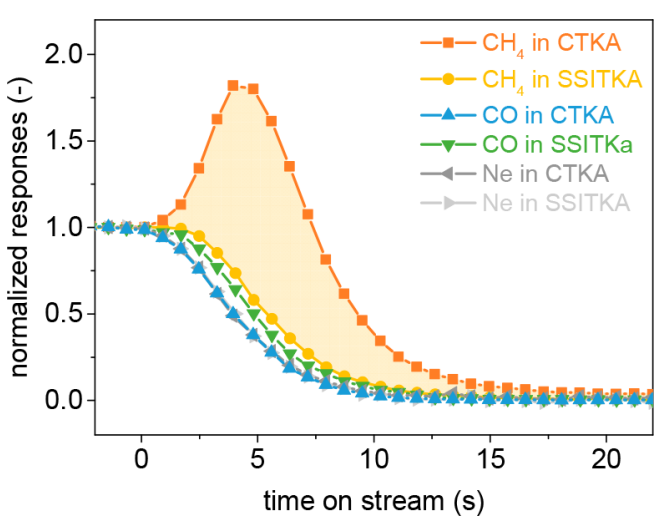

Figure 4. Normalized responses in SSITKA and backward CTKA. The extra- $\mathrm{CH}_{4}$ is defined by as the filled area between SSITKA $\mathrm{CH}_{4}$ (squares) and backward CTKA $\mathrm{CH}_{4}$ (circles) responses. Steady-state conditions: $T=260{ }^{\circ} \mathrm{C}, p_{\mathrm{H}_{2}}=450 \mathrm{mbar}, p_{\mathrm{CO}}=90$ mbar.

compare $\mathrm{CH}_{4}$ formation from two different transient experiments, viz. SSITKA and backward CTKA measurements. As only $\mathrm{CH}_{4}$ formed during SSITKA can be assigned to $\mathrm{CH}_{x}$ species present on the surface during steady state, we define the difference as "extra- $\mathrm{CH}_{4}$ ". We quantified this amount and converted it to an equivalent surface coverage by using the available Co surface area as determined by $\mathrm{H}_{2}$-chemisorption. This surface coverage of species generating extra- $\mathrm{CH}_{4}$ is compared to the CO coverage as determined by SSITKA. These data are displayed in Figure 2. Notably, at sufficiently high $\mathrm{H}_{2} / \mathrm{CO}$ ratios (either at relatively low $\mathrm{CO}$ partial pressure or relatively high $\mathrm{H}_{2}$ partial pressure), the amount of extra- $\mathrm{CH}_{4}$ is equivalent to the amount of $\mathrm{CO}$ adsorbed on the Co surface during the steady state preceding the CTKA switch. This result indicates that the extra- $\mathrm{CH}_{4}$ formed during the backward CTKA switch at high $\mathrm{H}_{2} / \mathrm{CO}$ ratio can be attributed solely to conversion of adsorbed $\mathrm{CO}$ to methane. At low $\mathrm{H}_{2} / \mathrm{CO}$ ratio, the amount of extra- $\mathrm{CH}_{4}$ is slightly higher than the amount of adsorbed CO. This cannot be accounted for by higher hydrocarbon fragments present on the surface that would dissociate and hydrogenate to $\mathrm{CH}_{4}$, because even at the lowest $\mathrm{H}_{2} / \mathrm{CO}$ ratio the $\mathrm{CH}_{4}$ selectivity is higher than $60 \%$ with the $\mathrm{CH}_{x}$ coverage being approximately $5 \%$ (Figure 2). As higher hydrocarbons formation typically follows an Anderson-Schulz-Flory distribution, the coverage of $\mathrm{C}_{2+}$-products must 
be even lower than 5\%. In this way, a pool of higher hydrocarbons cannot explain the extra- $\mathrm{CH}_{4}$ formed relative to the amount of adsorbed CO.

Another point worth mentioning about the data in Figure 4 is that the CO signal during the SSITKA switch exhibits a delay of $1 \mathrm{~s}$ with respect to the inert tracer gas. This delay is caused by the adsorption/desorption equilibrium of $\mathrm{CO}$ in the catalyst bed, also known as the chromatographic effect. The $\mathrm{CO}$ response in the $\mathrm{CO} / \mathrm{H}_{2} \rightarrow \mathrm{H}_{2}$ backward CTKA switch did not exhibit this delay. Close inspection reveals that the $\mathrm{CO}$ signal precedes the inert tracer signal. It implies that all $\mathrm{CO}$ adsorbed on the Co surface is consumed and leaves the reactor predominantly as $\mathrm{CH}_{4}$. An important corollary of this finding is that the overall barrier for $\mathrm{CO}$ hydrogenation to $\mathrm{CH}_{4}$ is lower than the $\mathrm{CO}$ desorption energy under methanation condition.

In order to understand the deviation between the amount of extra- $\mathrm{CH}_{4}$ and adsorbed $\mathrm{CO}$, we carried out temperatureprogrammed hydrogenation (TPH) experiments of samples in which the flow was switched from $\mathrm{CO} / \mathrm{H}_{2}$ to $\mathrm{Ar}$, followed by flushing in Ar for $6 \mathrm{~h}$ at $260{ }^{\circ} \mathrm{C}$. After cooling to room temperature, a TPH experiments was carried out. As shown in Figure 5, there are likely two carbon-containing surface species

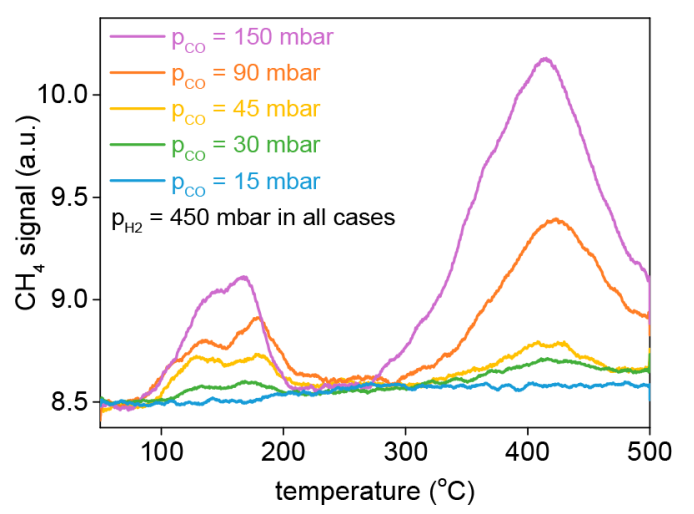

Figure 5. TPH profiles of the catalysts subjected to the methanation reaction at $260^{\circ} \mathrm{C}$ for $16 \mathrm{~h}$ time on stream followed by an Ar purge at $260{ }^{\circ} \mathrm{C}$ for $6 \mathrm{~h}$. The partial pressures presented in the graph relate to the reaction feed before the $\mathrm{H}_{2}$ purge.

that are hydrogenated at relatively low temperature, which is below $220{ }^{\circ} \mathrm{C}$. The data show that this carbon pool is not present at high $\mathrm{H}_{2} / \mathrm{CO}$ ratio, but is formed in increasing amounts when the $\mathrm{H}_{2} / \mathrm{CO}$ ratio is lowered. The nature of these carbon-containing surface intermediates remains unclear, but a particular property is that they can only be hydrogenated at sufficiently high $\mathrm{H}$ coverage as occurs during $\mathrm{TPH}$ and during the backward CTKA. Clearly, the surface will also contain even less-reactive $\mathrm{C}$ species as demonstrated by the reduction feature above $300{ }^{\circ} \mathrm{C}$. Similar observations have been reported by Winslow and Bell. ${ }^{35}$ Flushing a working $\mathrm{Ru}$ catalyst in $\mathrm{He}$ followed by temperature-programmed reduction in $\mathrm{D}_{2}$ led to two $\mathrm{CD}_{4}$ peaks designated as $\mathrm{C}_{\alpha}$ and $\mathrm{C}_{\beta}$, which are assigned to reactive intermediate and less reactive species causing deactivation, respectively.

Forward Chemical Transient Kinetic Analysis. We use forward CTKA to distinguish between rates of $\mathrm{C}$ and $\mathrm{O}$ hydrogenation. As the $\mathrm{H}$ coverage during methanation is high, both $\mathrm{C}$ and $\mathrm{O}$ hydrogenation reactions are fast. It is thus difficult to differentiate between the rates of these two reactions. Therefore, we decreased the $\mathrm{H}_{2}$ partial pressure
(200 mbar) and increased CO partial pressure (200 mbar) to amplify differences in $\mathrm{C}$ and $\mathrm{O}$ hydrogenation. The results of the forward CTKA switch are given in Figure 6. For these

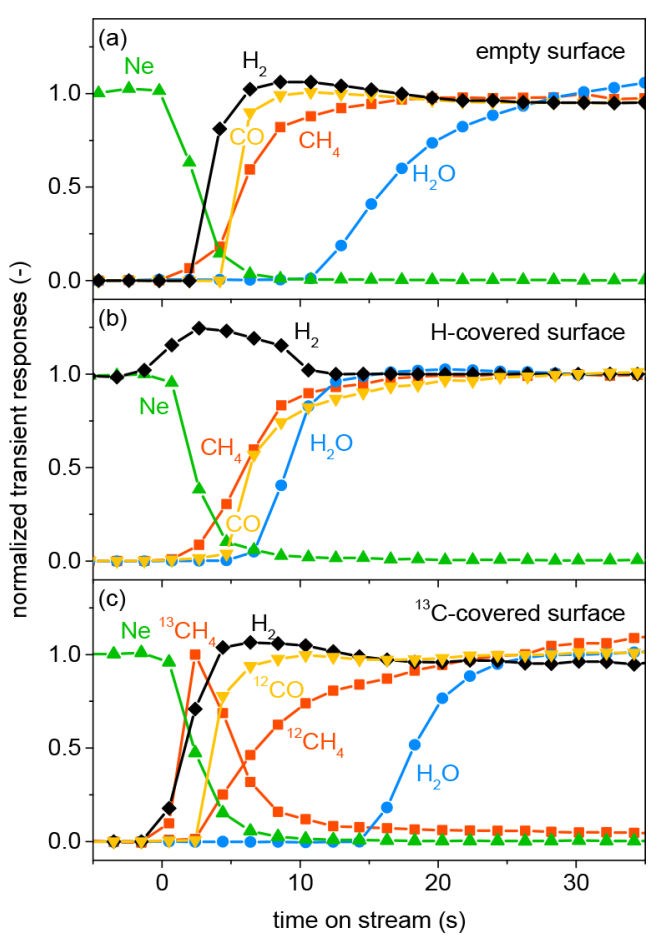

Figure 6. Forward transient on the initially empty cobalt surface (a), the $\mathrm{H}$-covered surface (b), and the ${ }^{13} \mathrm{C}$ precovered surface (c). The signal intensities are normalized based on the flow rate before and after the gas switch. Steady-state conditions: $T=260{ }^{\circ} \mathrm{C}, p_{\mathrm{H}_{2}}=200 \mathrm{mbar}$, $p_{\mathrm{CO}}=200$ mbar.

measurements, we analyzed both $\mathrm{CH}_{4}$ and $\mathrm{H}_{2} \mathrm{O}$ as primary products. Analyzing $\mathrm{H}_{2} \mathrm{O}$ during transient measurements is a challenge, because $\mathrm{H}_{2} \mathrm{O}$ will relatively strongly interact with various parts of the setup outside the catalyst bed (mainly with the stainless-steel capillary). Accordingly, we carefully established the systematic delay due to these nonspecific interactions (see the Supporting Information). The $\mathrm{H}_{2} \mathrm{O}$ delay values discussed below have been corrected for this systematic delay, as well as the delay caused by the chromatographic effect of $\mathrm{CO}$. As before, the $\mathrm{CH}_{4}$ delay has also been corrected for the chromatographic effect of CO.

As a reference case, we performed the forward CTKA switch on an empty cobalt surface. We obtained this state by flushing the in situ reduced Co catalyst in $\mathrm{Ar}$ for $2 \mathrm{~h}$, followed by cooling to reaction temperature in Ar. The forward transient involved an $\mathrm{Ar} / \mathrm{Ne} \rightarrow \mathrm{H}_{2} / \mathrm{CO}$ switch. Figure 6a shows that $\mathrm{CH}_{4}$ formation was delayed $2.5 \mathrm{~s}$ with respect to $\mathrm{Ne}$, while $\mathrm{H}_{2} \mathrm{O}$ was delayed approximately $6.5 \mathrm{~s}$ with respect to $\mathrm{Ne}$. The specific evolution of the $\mathrm{CH}_{4}, \mathrm{H}_{2} \mathrm{O}$, and $\mathrm{H}_{2}$ signals also evidence that $\mathrm{H}_{2}$ is more rapidly consumed for hydrogenation of $\mathrm{C}$ toward $\mathrm{CH}_{4}$ on an initially empty cobalt surface.

The same transient experiment was also performed on a catalyst that was precovered by $\mathrm{H}_{2}$ followed by a $\mathrm{H}_{2} / \mathrm{Ne} \rightarrow$ $\mathrm{CO} / \mathrm{H}_{2}$ switch. In this case, the $\mathrm{H}$ coverage before the switch is much higher than that at reaction condition. The corresponding results in Figure $6 \mathrm{~b}$ show a shorter $\mathrm{H}_{2} \mathrm{O}$ delay of $0.5 \mathrm{~s}$, while the decrease in the $\mathrm{CH}_{4}$ delay $(2 \mathrm{~s})$ is less pronounced. This comparison implies that the $\mathrm{H}_{2} \mathrm{O}$ delay on an empty surface is 
caused by a lack of adsorbed $\mathrm{H}$, and that the $\mathrm{O}$ hydrogenation profits more from higher $\mathrm{H}$ coverage than $\mathrm{C}$ hydrogenation.

We also carried out an experiment in which we precovered the surface with ${ }^{13} \mathrm{C}$ atoms by exposure to ${ }^{13} \mathrm{CO}$ flow at $260{ }^{\circ} \mathrm{C}$ for $0.5 \mathrm{~h}$, followed by Ar flushing to remove adsorbed ${ }^{13} \mathrm{CO}$. As demonstrated earlier, this procedure results in the deposition of $\mathrm{C}$ atoms on the Co surface. ${ }^{64,65}$ As shown in Figure $6 \mathrm{c}$, the forward transient $\mathrm{Ar} / \mathrm{Ne} \rightarrow \mathrm{H}_{2} / \mathrm{CO}$ of this ${ }^{13} \mathrm{C}$ atom precovered surface results in a significant longer $\mathrm{H}_{2} \mathrm{O}$ delay of $10 \mathrm{~s}, 3.5 \mathrm{~s}$ longer than on the empty surface and $9.5 \mathrm{~s}$ longer than on the $\mathrm{H}$ precovered surface. This increase in $\mathrm{H}_{2} \mathrm{O}$ delay is caused by two factors. On one hand, since the surface was partially covered by ${ }^{13} \mathrm{C}$ deposits, ${ }^{12} \mathrm{CO}$ adsorption and dissociation cannot proceed until a certain fraction of ${ }^{13} \mathrm{C}$ has been removed by hydrogenation. The correspondence between the $\mathrm{H}_{2}$ and ${ }^{13} \mathrm{CH}_{4}$ signals shown in Figure $6 \mathrm{~b}$ represents the strong dependence of $\mathrm{C}$ hydrogenation on $\mathrm{H}$ coverage. On the other hand, the preadsorbed ${ }^{13} \mathrm{C}$ deceases $\mathrm{H}$ coverage. In line with the observation that an increase in $\mathrm{H}$ coverage effectively shortens the $\mathrm{H}_{2} \mathrm{O}$ delay, the extra consumption of adsorbed $\mathrm{H}$ atoms caused by hydrogenation of precovered ${ }^{13} \mathrm{C}$ results in a longer $\mathrm{H}_{2} \mathrm{O}$ delay with respect to ${ }^{12} \mathrm{CH}_{4}$ on a ${ }^{13} \mathrm{C}$ precovered cobalt surface $(6 \mathrm{~s})$ as compared to the empty surface $(4 \mathrm{~s})$. We stress that the competition between $\mathrm{C}$ and $\mathrm{O}$ hydrogenation is partially due to the low $\mathrm{H}_{2} / \mathrm{CO}$ ratio in this case. The findings above also suggest that the strong dependence of $\mathrm{H}_{2} \mathrm{O}$ formation on the $\mathrm{H}$ coverage significantly contributes to the reaction order with respect to $\mathrm{H}_{2}$.

Microkinetic Modeling. A common approach to distinguish mechanisms is to fit steady-state catalytic data to a microkinetic model based on a mechanism consisting of elementary reaction steps. A major limitation of transient kinetic studies of $\mathrm{CO}$ hydrogenation is that the $\mathrm{H}$ coverage cannot be explicitly measured. This dependence is therefore often lumped into hydrogenation reaction rate constants. Here, we take a different approach in which we use transient data to fit a microkinetic model for $\mathrm{CO}$ hydrogenation involving $\mathrm{H}$ explicitly as a surface species. The elementary reaction steps that make up the microkinetic model for $\mathrm{CO}$ hydrogenation is given in Figure 7. The alternative kinetic model that involves

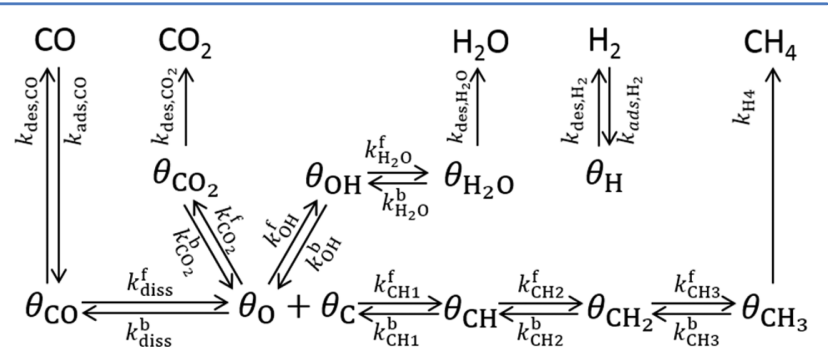

Figure 7. Schematic presentation of reaction model based on direct $\mathrm{CO}$ dissociation mechanism.

$\mathrm{H}$-assisted $\mathrm{CO}$ dissociation is provided in the Supporting Information. We will first discuss the set of coupled nonlinear differential equations that describes the transient coverages of surface adsorbed species, which are the reaction intermediates. The surface coverage of $\mathrm{CO}$ can be described as follows:

$$
\begin{aligned}
\frac{\mathrm{d} \theta_{\mathrm{CO}}}{\mathrm{d} t}= & k_{\mathrm{ads}, \mathrm{CO}} p_{\mathrm{CO}} \theta_{\mathrm{v}}-k_{\mathrm{des}, \mathrm{CO}} \theta_{\mathrm{CO}}-k_{\mathrm{diss}}^{\mathrm{f}} \theta_{\mathrm{v}} \theta_{\mathrm{CO}}+k_{\mathrm{diss}}^{\mathrm{b}} \theta_{\mathrm{C}} \theta_{\mathrm{O}} \\
& -k_{\mathrm{CO}_{2}}^{\mathrm{f}} \theta_{\mathrm{CO}} \theta_{\mathrm{O}}+k_{\mathrm{CO}_{2}}^{\mathrm{b}} \theta_{\mathrm{v}} \theta_{\mathrm{CO}_{2}}
\end{aligned}
$$

The balance for $\mathrm{CH}_{x}$ species involves $\mathrm{CH}_{x}$ hydrogenation/ dehydrogenation steps and also the $\mathrm{CO}$ dissociation for the $\mathrm{C}$ intermediate:

$$
\begin{aligned}
& \frac{\mathrm{d} \theta_{\mathrm{C}}}{\mathrm{d} t}=k_{\mathrm{diss}}^{\mathrm{f}} \theta_{\mathrm{v}} \theta_{\mathrm{CO}}-k_{\mathrm{diss}}^{\mathrm{b}} \theta_{\mathrm{C}} \theta_{\mathrm{O}}-k_{\mathrm{CH}}^{\mathrm{f}} \theta_{\mathrm{H}} \theta_{\mathrm{C}}+k_{\mathrm{CH}}^{\mathrm{b}} \theta_{\mathrm{v}} \theta_{\mathrm{CH}} \\
& \frac{\mathrm{d} \theta_{\mathrm{CH}}}{\mathrm{d} t}=k_{\mathrm{CH}}^{\mathrm{f}} \theta_{\mathrm{H}} \theta_{\mathrm{C}}-k_{\mathrm{CH}}^{\mathrm{b}} \theta_{\mathrm{v}} \theta_{\mathrm{CH}}-k_{\mathrm{CH}_{2}}^{\mathrm{f}} \theta_{\mathrm{H}} \theta_{\mathrm{CH}}+k_{\mathrm{CH}_{2}}^{\mathrm{b}} \theta_{\mathrm{v}} \theta_{\mathrm{CH}_{2}} \\
& \frac{\mathrm{d} \theta_{\mathrm{CH}_{2}}}{\mathrm{~d} t}=k_{\mathrm{CH}_{2}}^{\mathrm{f}} \theta_{\mathrm{H}} \theta_{\mathrm{CH}}-k_{\mathrm{CH}_{2}}^{\mathrm{b}} \theta_{\mathrm{v}} \theta_{\mathrm{CH}_{2}}-k_{\mathrm{CH}_{3}}^{\mathrm{f}} \theta_{\mathrm{H}} \theta_{\mathrm{CH}_{2}} \\
& \quad+k_{\mathrm{CH}_{3}}^{\mathrm{b}} \theta_{\mathrm{v}} \theta_{\mathrm{CH}_{3}} \\
& \frac{\mathrm{d} \theta_{\mathrm{CH}_{3}}}{\mathrm{~d} t}=k_{\mathrm{CH}_{3}}^{\mathrm{f}} \theta_{\mathrm{H}} \theta_{\mathrm{CH}_{2}}-k_{\mathrm{CH}_{3}}^{\mathrm{b}} \theta_{\mathrm{v}} \theta_{\mathrm{CH}_{3}}-k_{\mathrm{CH}_{4}} \theta_{\mathrm{H}} \theta_{\mathrm{CH}_{3}}
\end{aligned}
$$

The balance for $\mathrm{OH}_{x}$ intermediates involves $\mathrm{CO}$ dissociation, removal of $\mathrm{O}$ via $\mathrm{H}_{2} \mathrm{O}$ and $\mathrm{CO}_{2}$ :

$$
\begin{aligned}
\frac{\mathrm{d} \theta_{\mathrm{O}}}{\mathrm{d} t}= & k_{\mathrm{diss}}^{\mathrm{f}} \theta_{\mathrm{v}} \theta_{\mathrm{CO}}-k_{\mathrm{diss}}^{\mathrm{b}} \theta_{\mathrm{C}} \theta_{\mathrm{O}}-k_{\mathrm{OH}}^{\mathrm{f}} \theta_{\mathrm{H}} \theta_{\mathrm{O}}+k_{\mathrm{OH}}^{\mathrm{b}} \theta_{\mathrm{v}} \theta_{\mathrm{OH}} \\
& +k_{2 \mathrm{OH}}^{\mathrm{f}} \theta_{\mathrm{OH}} \theta_{\mathrm{OH}}-k_{2 \mathrm{OH}}^{\mathrm{b}} \theta_{\mathrm{O}} \theta_{\mathrm{H}_{2} \mathrm{O}}-k_{\mathrm{CO}_{2}}^{\mathrm{f}} \theta_{\mathrm{CO}} \theta_{\mathrm{O}} \\
& +k_{\mathrm{CO}_{2}}^{\mathrm{b}} \theta_{\mathrm{v}} \theta_{\mathrm{CO}_{2}} \\
\frac{\mathrm{d} \theta_{\mathrm{OH}}}{\mathrm{d} t}= & k_{\mathrm{OH}}^{\mathrm{f}} \theta_{\mathrm{H}} \theta_{\mathrm{O}}-k_{\mathrm{OH}}^{\mathrm{b}} \theta_{\mathrm{v}} \theta_{\mathrm{OH}}-2 k_{2 \mathrm{OH}}^{\mathrm{f}} \theta_{\mathrm{OH}} \theta_{\mathrm{OH}} \\
& +2 k_{2 \mathrm{OH}}^{\mathrm{b}} \theta_{\mathrm{O}} \theta_{\mathrm{H}_{2} \mathrm{O}}-k_{\mathrm{H}_{2} \mathrm{O}}^{\mathrm{f}} \theta_{\mathrm{H}} \theta_{\mathrm{OH}}+k_{\mathrm{H}_{2} \mathrm{O}}^{\mathrm{b}} \theta_{\mathrm{v}} \theta_{\mathrm{H}_{2} \mathrm{O}} \\
\frac{\mathrm{d} \theta_{\mathrm{H}_{2} \mathrm{O}}=}{\mathrm{d} t} & k_{\mathrm{H}_{2} \mathrm{O}}^{\mathrm{f}} \theta_{\mathrm{H}} \theta_{\mathrm{OH}}-k_{\mathrm{CO}_{2}}^{\mathrm{b}} \theta_{\mathrm{v}} \theta_{\mathrm{H}_{2} \mathrm{O}}+k_{2 \mathrm{OH}}^{\mathrm{f}} \theta_{\mathrm{OH}} \theta_{\mathrm{OH}} \\
& -k_{2 \mathrm{OH}}^{\mathrm{b}} \theta_{\mathrm{O}} \theta_{\mathrm{H}_{2} \mathrm{O}}-k_{\mathrm{des}, \mathrm{H}_{2} \mathrm{O}} \theta_{\mathrm{H}_{2} \mathrm{O}}
\end{aligned}
$$

The balance for adsorbed $\mathrm{CO}_{2}$ is given by

$$
\frac{\mathrm{d} \theta_{\mathrm{CO}_{2}}}{\mathrm{~d} t}=k_{\mathrm{CO}_{2}}^{\mathrm{f}} \theta_{\mathrm{O}} \theta_{\mathrm{CO}}-k_{\mathrm{CO}_{2}}^{\mathrm{b}} \theta_{\mathrm{v}} \theta_{\mathrm{CO}_{2}}-k_{\mathrm{des}, \mathrm{CO}_{2}} \theta_{\mathrm{CO}_{2}}
$$

Finally, we provide the balance for the $H$ surface intermediate

$$
\begin{aligned}
\frac{\mathrm{d} \theta_{\mathrm{H}}}{\mathrm{d} t}= & 2 k_{\mathrm{ads}, \mathrm{H}_{2}} p_{\mathrm{H}_{2}} \theta_{\mathrm{v}} \theta_{\mathrm{v}}-2 k_{\mathrm{des}, \mathrm{H}_{2}} \theta_{\mathrm{H}} \theta_{\mathrm{H}} \\
& -\theta_{\mathrm{H}}\left(k_{\mathrm{CH}}^{\mathrm{f}} \theta_{\mathrm{C}}+k_{\mathrm{CH}_{2}}^{\mathrm{f}} \theta_{\mathrm{CH}}+k_{\mathrm{CH}_{3}}^{\mathrm{f}} \theta_{\mathrm{CH}_{2}}+k_{\mathrm{CH}_{4}} \theta_{\mathrm{CH}_{3}}\right. \\
& \left.+k_{\mathrm{OH}}^{\mathrm{f}} \theta_{\mathrm{O}}+k_{\mathrm{H}_{2} \mathrm{O}}^{\mathrm{f}} \theta_{\mathrm{OH}}\right)+\theta_{\mathrm{v}}\left(k_{\mathrm{CH}}^{\mathrm{b}} \theta_{\mathrm{CH}}+k_{\mathrm{CH}_{2}}^{\mathrm{b}} \theta_{\mathrm{CH}_{2}}\right. \\
& \left.+k_{\mathrm{CH}_{3}}^{\mathrm{b}} \theta_{\mathrm{CH}_{3}}+k_{\mathrm{OH}}^{\mathrm{b}} \theta_{\mathrm{OH}}+k_{\mathrm{H}_{2} \mathrm{O}}^{\mathrm{b}} \theta_{\mathrm{H}_{2} \mathrm{O}}\right)
\end{aligned}
$$

where $\theta_{\mathrm{v}}$ refers the vacant sites on surface.

An additional constraint is that the sum of all coverages is unity:

$$
\begin{aligned}
\theta_{\mathrm{CO}} & +\theta_{\mathrm{C}}+\theta_{\mathrm{CH}}+\theta_{\mathrm{CH}_{2}}+\theta_{\mathrm{CH}_{3}}+\theta_{\mathrm{O}}+\theta_{\mathrm{CO}_{2}}+\theta_{\mathrm{OH}} \\
& +\theta_{\mathrm{H}_{2} \mathrm{O}}+\theta_{\mathrm{H}}+\theta_{\mathrm{v}} \\
= & 1
\end{aligned}
$$

We then used a procedure to fit this model to experimental transient $\mathrm{CH}_{4}$ signals (comprising SSITKA, forward CTKA and 
backward CTKA). We choose transient data obtained at a high $\mathrm{H}_{2} / \mathrm{CO}$ ratio of 15 ( $p_{\mathrm{CO}}=30 \mathrm{mbar}, p_{\mathrm{H}_{2}}=450 \mathrm{mbar}$ and $T=$ $260{ }^{\circ} \mathrm{C}$ ) so as to ensure a high $\mathrm{CH}_{4}$ selectivity of approximately $90 \%$ and a chain-growth probability smaller than 0.1 . A leastsquares objective function is used as following

$$
\begin{aligned}
\varepsilon= & \sum\left(f_{\text {forward }}^{\text {model }}-f_{\text {forward }}^{\text {exp }}\right)^{2}+\sum\left(f_{\text {SSITKA }}^{\text {model }}-f_{\text {SSITKA }}^{\text {exp }}\right)^{2} \\
& +\sum\left(f_{\text {backward }}^{\text {model }}-f_{\text {backward }}^{\text {exp }}\right)^{2}+w\left(\left(n_{\text {CO }}^{\text {model }}-n_{\text {CO }}^{\text {exp }}\right)^{2}\right. \\
& \left.+\left(n_{\mathrm{H}_{2}}^{\text {model }}-n_{\mathrm{H}_{2}}^{\text {exp }}\right)^{2}\right)
\end{aligned}
$$

in which $f$ denotes the normalized transient response of methane, $n$ the reaction order, and $w$ is a factor for giving a similar weight to the reaction orders as that to the transient data. To decrease the number of unknown variables, we introduced equilibrium constants for several surface reactions based on DFT calculations for the $\mathrm{Co}(11 \overline{2} 1)$ surface (Table S1 in the Supporting Information). Finally, a total of 16 rate constants were fitted. The boundary conditions and the details about the fitting procedure are discussed in the Supporting Information. The fitting results are listed in Table 2 (the results

\section{Table 2. Rate Constants Determined by Model Fitting}

\begin{tabular}{lll} 
& $k_{\mathrm{f}}\left(\mathrm{s}^{-1}\right)$ & $k_{\mathrm{b}}\left(\mathrm{s}^{-1}\right)$ \\
adsorption/desorption & & \\
$\mathrm{CO}+* \rightleftarrows \mathrm{CO}$ & $4.8 \times 10^{1}$ & $8.1 \times 10^{-1}$ \\
$\mathrm{H}_{2}+2 * \rightleftarrows 2 \mathrm{H}^{*}$ & $7.2 \times 10^{3}$ & $2.5 \times 10^{6}$ \\
$\mathrm{H}_{2} \mathrm{O}^{*} \rightarrow \mathrm{H}_{2} \mathrm{O}+*$ & $7.7 \times 10^{1}$ & \\
$\mathrm{CO}_{2}^{*} \rightarrow \mathrm{CO}_{2}+*$ & $7.7 \times 10^{3}$ & \\
$\mathrm{CO}$ dissociation & & \\
$\mathrm{CO}+* \rightleftarrows \mathrm{C}^{*}+\mathrm{O}^{*}$ & $5.2 \times 10^{-1}$ & $7.3 \times 10^{1}$ \\
$\mathrm{CH}_{4}$ formation & & \\
$\mathrm{C}^{*}+\mathrm{H}^{*} \rightleftarrows \mathrm{CH}^{*}+*$ & $2.3 \times 10^{3}$ & $2.6 \times 10^{1}$ \\
$\mathrm{CH}^{*}+\mathrm{H}^{*} \rightleftarrows \mathrm{CH}_{2}^{*}+*$ & $1.9 \times 10^{4}$ & $2.2 \times 10^{4}$ \\
$\mathrm{CH}_{2}^{*}+\mathrm{H}^{*} \rightleftarrows \mathrm{CH}_{3}^{*}+*$ & $2.8 \times 10^{3}$ & $1.0 \times 10^{2}$ \\
$\mathrm{CH}_{3}^{*}+\mathrm{H}^{*} \rightarrow \mathrm{CH}_{4}+2 *$ & $8.7 \times 10^{2}$ & \\
$\mathrm{H}_{2} \mathrm{O}$ formation & & \\
$\mathrm{O}^{*}+\mathrm{H}^{*} \rightleftarrows \mathrm{OH}^{*}+*$ & $1.7 \times 10^{2}$ & $9.3 \times 10^{-3}$ \\
$\mathrm{OH}^{*}+\mathrm{H}^{*} \rightleftarrows \mathrm{H}_{2} \mathrm{O}^{*}+*$ & $4.7 \times 10^{2}$ & $1.5 \times 10^{-1}$ \\
$2 \mathrm{OH}^{*} \rightleftarrows \mathrm{H}_{2} \mathrm{O}^{*}+\mathrm{O}^{*}$ & $2.8 \times 10^{6}$ & $2.1 \times 10^{7}$ \\
$\mathrm{CO}_{2}$ formation & & \\
$\mathrm{CO}^{*}+\mathrm{O}^{*} \rightleftarrows \mathrm{CO}_{2}^{*}+*$ & $1.1 \times 10^{-1}$ & $5.9 \times 10^{-6}$ \\
\hline
\end{tabular}

based on $\mathrm{H}$-assisted $\mathrm{CO}$ dissociation are listed in Table S2). The good correspondence between the model and the experimental data is shown in Figure 8. The goodness of fit for the microkinetic model based on direct CO dissociation $\left(R^{2}\right.$
$=0.95)$ is higher than the one on $\mathrm{H}$-assisted $\mathrm{CO}$ dissociation $\left(R^{2}=0.88\right)$. We emphasize that this criterion alone is not sufficient to rule out that a $\mathrm{H}$-assisted mechanism occurs in parallel with direct $\mathrm{CO}$ dissociation. Therefore, we discuss the fitting results for a model based on $\mathrm{H}$-assisted $\mathrm{CO}$ dissociation in the Supporting Information.

Based on the fitted data, we then analyzed the different kinetic regimes of the $\mathrm{CO}$ hydrogenation reaction by determining the degree of rate control (DRC, see the Supporting Information). By doing so, one can identify to what extent particular elementary reaction steps control the overall CO conversion rate. ${ }^{66,67}$ A positive DRC value $\left(X_{\mathrm{DRC}, i}\right)$ indicates that the overall reaction rate increases when the rate of elementary step $i$ is increased. On the contrary, steps with a negative $X_{\mathrm{DRC}, i}$ are rate-inhibiting steps that slow down the overall rate. The results are presented in Table 3 in terms of

Table 3. Lumped Degree of Rate Control Values Obtained at 30 mbar $\mathrm{CO}$ and 450 mbar $\mathrm{H}_{2}$

\begin{tabular}{lc}
\multicolumn{1}{c}{ reaction } & $X_{\mathrm{DRC}}$ \\
$\mathrm{CO}$ adsorption & $-4.9 \times 10^{-2}$ \\
$\mathrm{H}_{2}$ adsorption & $3.6 \times 10^{-4}$ \\
$\mathrm{CO}$ dissociation & 0.15 \\
$\mathrm{C}$ hydrogenation & 0.62 \\
$\mathrm{O}$ hydrogenation & 0.24 \\
$\mathrm{CO}_{2}$ formation & $3.2 \times 10^{-2}$ \\
\hline
\end{tabular}

lumped DRC parameters for key reaction steps in the $\mathrm{CO}$ hydrogenation mechanism. A detailed list of DRC values is provided in the Supporting Information. Table 3 shows that C hydrogenation steps control the methanation reaction most. The other reaction that controls the overall rate is $O$ hydrogenation for which we identify a $X_{\mathrm{DRC}}$ of 0.24 . The $\mathrm{DRC}$ for the $\mathrm{C}-\mathrm{O}$ bond scission step is only 0.15 , emphasizing its weak rate-controlling nature with the hydrogenation steps. The DRC analysis based on the $\mathrm{H}$-assisted $\mathrm{CO}$ dissociation mechanism shows qualitatively similar results (Table S3), suggesting that the conclusion of slow $\mathrm{C}$ and $\mathrm{O}$ hydrogenation at methanation conditions is independent of the $\mathrm{CO}$ dissociation mechanism. These conclusions are in good agreement with a recent theoretical study ${ }^{68}$ and also the forward transient experiments in this study.

An important conclusion from this kinetic analysis is that $\mathrm{CO}$ dissociation is not the rate-limiting step on cobalt at sufficiently high $\mathrm{H}_{2} / \mathrm{CO}$ ratio and high temperature (pertaining to a relatively empty surface). Instead, the hydrogenation of the $\mathrm{O}$ and especially $\mathrm{C}$ species deriving from $\mathrm{CO}$ dissociation control

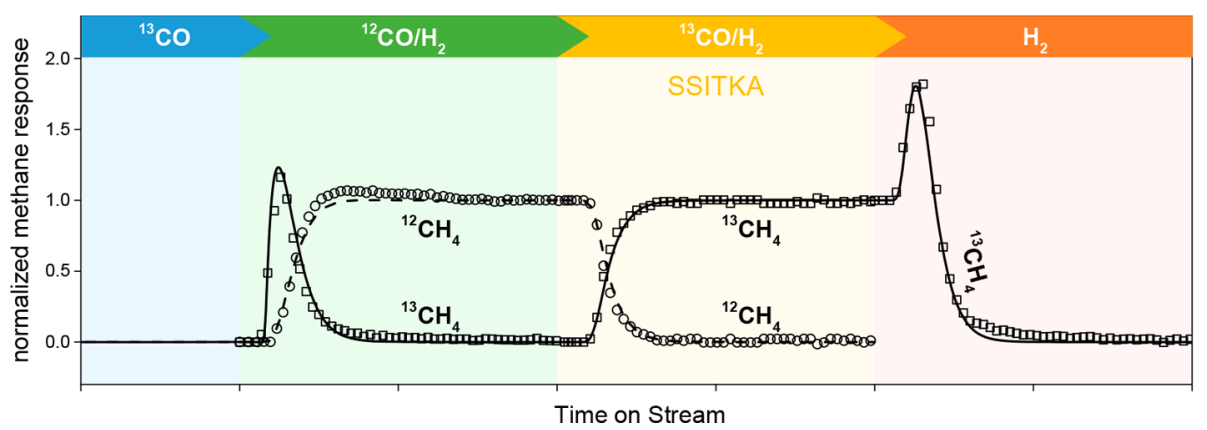

Figure 8. Combined transient data (points) and model fitting (line) based on direct CO dissociation mechanism. Steady-state conditions: $T=260$ ${ }^{\circ} \mathrm{C}, p_{\mathrm{H}_{2}}=450 \mathrm{mbar}, p_{\mathrm{CO}}=30 \mathrm{mbar}$. 

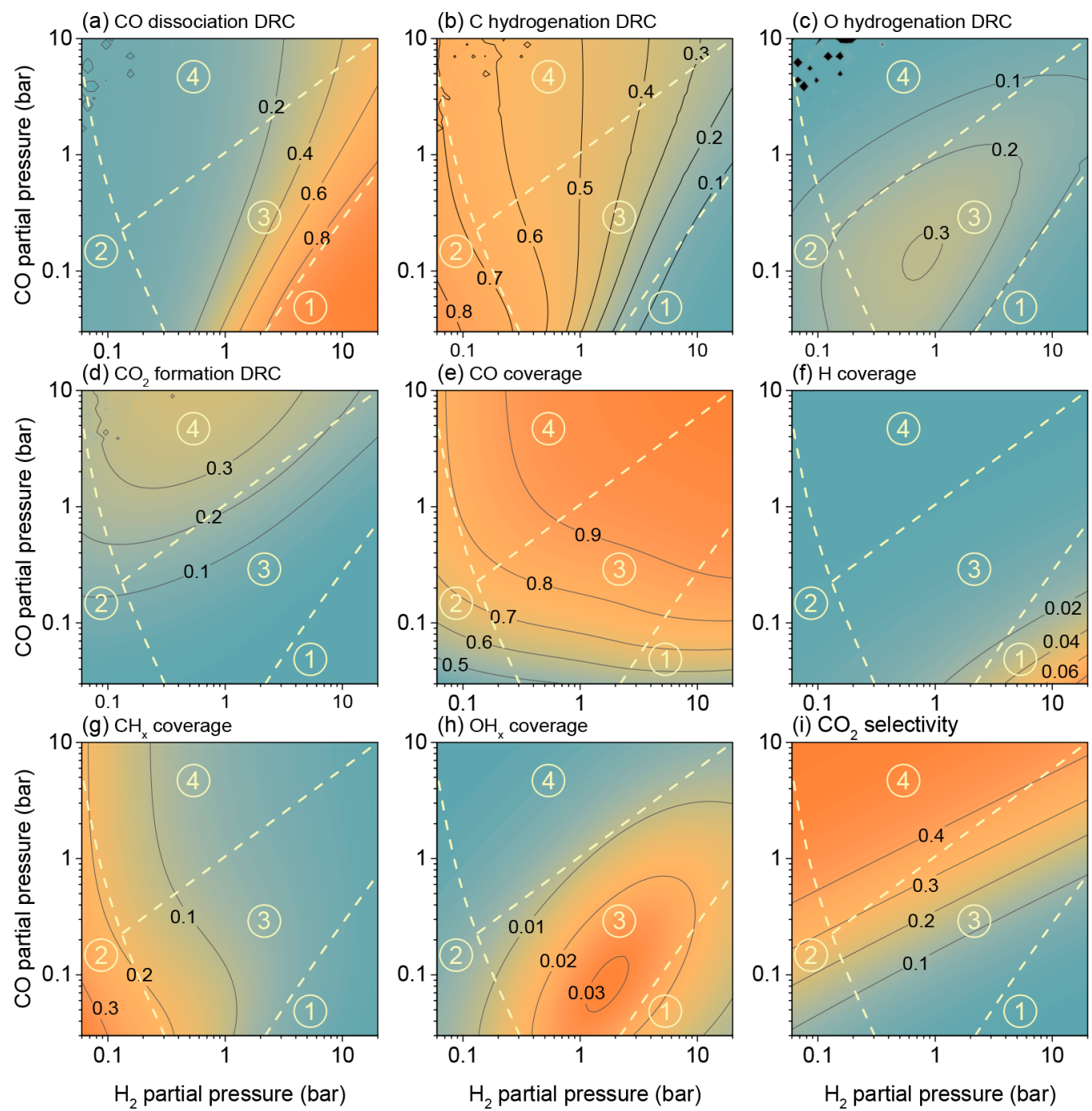

Figure 9. Degree of rate control (a-d), surface coverage (e-h) and $\mathrm{CO}_{2}$ selectivity (i) as a function of $\mathrm{CO}$ and $\mathrm{H}_{2}$ partial pressures based on a microkinetic model using parameters obtained by fitting of transient data for the methanation reaction on $\mathrm{Co} / \mathrm{SiO}_{2}\left(\right.$ conditions: $T=260{ }^{\circ} \mathrm{C}, p_{\mathrm{H}_{2}}=$ 450 mbar, $p_{\mathrm{CO}}=30$ mbar.).

the reaction rate. This finding is consistent with the experimental observation that the absolute value of $\mathrm{H}_{2}$ reaction order for $\mathrm{CH}_{4}$ formation is larger than that of $\mathrm{CO}$ reaction order, implying $\mathrm{H}_{2}$ partial pressure affects the reaction more strongly than $\mathrm{CO}$ does. The influence of $\mathrm{H}_{2}$ partial pressure on the reaction rate is larger, as the $\mathrm{H}$ coverage is directly related to the $\mathrm{H}_{2}$ partial pressure; the influence of $\mathrm{CO}$ partial pressure is smaller as it indirectly influences the reaction by hindering $\mathrm{H}_{2}$ adsorption.

The present work demonstrates that multiple elementary reaction steps can contribute to the rate control of the methanation reaction. The positive order with respect to $\mathrm{H}_{2}$ is due to the rate-controlling nature of $\mathrm{C}$ and $\mathrm{O}$ hydrogenation steps. The negative $\mathrm{CO}$ reaction order is due to the competition between $\mathrm{CO}$ and $\mathrm{H}_{2}$ adsorption, in which an increase in $\mathrm{CO}$ coverage decreases the $\mathrm{H}$ coverage that is needed for catalyzing the rate-controlling $\mathrm{C}$ and $\mathrm{O}$ hydrogenation steps.

Microkinetics Simulations. We employ the fitted microkinetic model to explore the effect of a wider range of $\mathrm{CO}$ and $\mathrm{H}_{2}$ partial pressures, that is, from 0.06 to 20 bar and $0.03-10$ bar, respectively. The output of these microkinetic simulations is presented in Figure 9 in the form of a DRC analysis, surface coverages, and $\mathrm{CO}_{2}$ selectivity. Four regimes can be distinguished on the basis of the DRC values. In regime 1, the $\mathrm{H}_{2}$ partial pressure is substantially higher than the $\mathrm{CO}$ partial pressure. Consequently, $\mathrm{CO}$ coverage is low and $\mathrm{H}$ coverage high. In this regime, $\mathrm{C}$ and $\mathrm{O}$ atoms derived from $\mathrm{CO}$ dissociation are rapidly removed as $\mathrm{CH}_{4}$ and $\mathrm{H}_{2} \mathrm{O}$, respectively, and $\mathrm{CO}$ dissociation becomes increasingly rate-controlling with increasing $\mathrm{H}_{2}$ pressure. Thus, $\mathrm{C}$ and $\mathrm{O}$ hydrogenation steps do not limit the $\mathrm{CO}$ conversion rate, but $\mathrm{CO}$ dissociation does. In regime 2, the surface contains a significant amount of $\mathrm{CH}_{x}$ intermediates as the lack of $\mathrm{H}$ atoms limits their hydrogenation. Regime 3 presents the conditions with moderate $\mathrm{H}_{2} / \mathrm{CO}$ ratio (the diagonal lines in Figure 9 refer to $\mathrm{a}_{2} / \mathrm{CO}$ ratio of 2), a condition close to the FT condition. $\mathrm{CO}$ dissociation and $\mathrm{C}$ hydrogenation steps largely contribute to the overall rate control. Due to the accumulation of $\mathrm{OH}_{x}$ intermediates on the surface (Figure 9g), $\mathrm{H}_{2} \mathrm{O}$ formation considerably controls the $\mathrm{CO}$ conversion rate in this regime. This is in line with recent DFT-based microkinetics simulations. ${ }^{68}$ Meanwhile, Regime 4 refers to the lean $\mathrm{H}$ condition, under which the cobalt surface is fully covered by $\mathrm{CO}$ (Figure 9h). In this case, $\mathrm{O}$ is 
predominantly removed as $\mathrm{CO}_{2}$ (Figure 9i), as the surface lacks $\mathrm{H}$ atoms for $\mathrm{O}$ hydrogenation.

These regimes provide us some insight into the different kinetic regimes one might encounter when varying the $\mathrm{H}_{2} / \mathrm{CO}$ ratio. Notably, regime 4 is an extreme case, stemming from the higher $\mathrm{CO}_{2}$ selectivity observed at $260{ }^{\circ} \mathrm{C}$ than at the actual FT temperature. As expected, the rate-controlling steps at conditions close to FT conditions (upper right corner in Figure 9) differ from those under methanation conditions (lower right corner in Figure 9). It appears that the very different composition of the surface adsorbed layer at lower temperature will have a significant impact on the ratecontrolling nature of the different elementary reaction steps. These aspects are the focus of our companion paper which uses similar transient methodologies to interrogate the reaction mechanism of the $\mathrm{Co} / \mathrm{SiO}_{2}$ catalyst under conditions close to those encountered in practical FT synthesis.

\section{CONCLUSIONS}

The mechanism of $\mathrm{CO}$ hydrogenation to $\mathrm{CH}_{4}$ at $260{ }^{\circ} \mathrm{C}$ on a cobalt catalyst is interrogated by different types of transient kinetic measurements including SSITKA and backward and forward CTKA. The dependence of $\mathrm{CH}_{x}$ residence time as determined by SSITKA $\left({ }^{12} \mathrm{CO} / \mathrm{H}_{2} \rightarrow{ }^{13} \mathrm{CO} / \mathrm{H}_{2}\right)$ on $\mathrm{CO}$ and $\mathrm{H}_{2}$ partial pressure indicates that the $\mathrm{CH}_{4}$ formation rate is mainly controlled by $\mathrm{CH}_{x}$ hydrogenation rather than $\mathrm{CO}$ dissociation. The backward $\mathrm{CO} / \mathrm{H}_{2} \rightarrow \mathrm{H}_{2}$ CTKA emphasizes the importance of $\mathrm{H}$ coverage on the slow $\mathrm{CH}_{x}$ hydrogenation step. The $\mathrm{H}$ coverage strongly depends on the $\mathrm{CO}$ coverage, which is mainly determined by $\mathrm{CO}$ partial pressure. By combining SSITKA and backward CTKA, it is established that the additional $\mathrm{CH}_{4}$ obtained during CTKA in comparison to SSITKA is nearly equal in amount to the amount of $\mathrm{CO}$ adsorbed on the cobalt surface. This implies that under the given conditions the overall barrier for $\mathrm{CO}$ hydrogenation to $\mathrm{CH}_{4}$ is lower than the $\mathrm{CO}$ adsorption energy. Forward CTKA measurements also qualitatively show that $\mathrm{O}$ hydrogenation is relatively slow compared to $\mathrm{CO}$ dissociation. The combined transient kinetic data are captured in an explicit microkinetic model for the methanation reaction. The model fitting shows that a mechanism involving direct $\mathrm{CO}$ dissociation better represents the data than a mechanism in which $\mathrm{H}$-assisted $\mathrm{CO}$ dissociation is assumed. Microkinetics simulations based on the fitted parameters show the highest DRC for $\mathrm{C}$ hydrogenation and lower DRC for $\mathrm{O}$ hydrogenation and $\mathrm{CO}$ dissociation at typical methanation conditions. These simulations are also used to explore different conditions depending on $\mathrm{CO}$ and $\mathrm{H}_{2}$ partial pressure. This leads to four kinetic regimes in which $\mathrm{CO}$ consumption rate is controlled by $\mathrm{CO}$ dissociation, $\mathrm{C}$ hydrogenation, $\mathrm{O}$ hydrogenation, and $\mathrm{CO}_{2}$ formation.

\section{ASSOCIATED CONTENT}

\section{S Supporting Information}

The Supporting Information is available free of charge on the ACS Publications website at DOI: 10.1021/acscatal.7b02757.

(1) Correction of water transient responses; (2) validation of differential operation; (3) $\mathrm{H}$-assisted $\mathrm{CO}$ dissociation mechanism based reaction model; (4) equilibrium constants by DFT calculation; (5) boundary conditions; (6) random sampling based global optimization approach; (7) direct $\mathrm{CO}$ dissociation and $\mathrm{H}$-assisted
CO dissociation; (8) degree of rate control determination (PDF)

\section{AUTHOR INFORMATION}

\section{Corresponding Author}

*E-mail: e.j.m.hensen@tue.nl.

ORCID 우

Ivo A. W. Filot: 0000-0003-1403-8379

Emiel J. M. Hensen: 0000-0002-9754-2417

Notes

The authors declare no competing financial interest.

\section{REFERENCES}

(1) Dry, M. E.; Hoogendoorn, J. C. Catal. Rev.: Sci. Eng. 1981, 23, 265-278.

(2) Dry, M. E. Catal. Today 2002, 71, 227-241.

(3) List, B. Angew. Chem., Int. Ed. 2014, 53, 8528-8530.

(4) Fischer, F.; Tropsch, H. Ber. Dtsch. Chem. Ges. B 1923, 56, 24182428.

(5) Fischer, F.; Tropsch, H. Ber. Dtsch. Chem. Ges. B 1926, 59, 923925.

(6) Khodakov, A. Y.; Chu, W.; Fongarland, P. Chem. Rev. 2007, 107, 1692-1744.

(7) Yates, I. C.; Satterfield, C. N. Energy Fuels 1991, 5, 168-173.

(8) Van Der Laan, G. P.; Beenackers, A. A. C. M. Catal. Rev.: Sci. Eng. 1999, 41, 255-318.

(9) Haghtalab, A.; Nabipoor, M.; Farzad, S. Fuel Process. Technol. 2012, 104, 73-79.

(10) Wojciechowski, B. W. Catal. Rev.: Sci. Eng. 1988, 30, 629-702.

(11) Iglesia, E.; Reyes, S. C.; Madon, R. J.; Soled, S. L. Adv. Catal. 1993, 39, 221-302.

(12) Kuipers, E. W.; Vinkenburg, I. H.; Oosterbeek, H. J. Catal. 1995, 152, 137-146.

(13) Happel, J.; Kiang, S.; Spencer, J. L.; Oki, S.; Hnatow, M. A. J. Catal. 1977, 50, 429-440.

(14) Happel, J.; Suzuki, I.; Kokayeff, P.; Fthenakis, V. J. Catal. 1980, $65,59-77$.

(15) Happel, J.; Cheh, H. Y.; Otarod, M.; Ozawa, S.; Severdia, A. J.; Yoshida, T.; Fthenakis, V. J. Catal. 1982, 75, 314-328.

(16) Bennett, C. O. Catal. Rev.: Sci. Eng. 1976, 13, 121-148.

(17) Matsumoto, H.; Bennett, C. O. J. Catal. 1978, 53, 331-344.

(18) Biloen, P.; Helle, J. N.; Sachtler, W. M. H. J. Catal. 1979, 58, 95-107.

(19) Biloen, P. J. Mol. Catal. 1983, 21, 17-24.

(20) Soong, Y.; Biloen, P. Langmuir 1985, 1, 768-770.

(21) Frennet, A.; Hubert, C. J. Mol. Catal. A: Chem. 2000, 163, 163188.

(22) Shannon, S. L.; Goodwin, J. G. Chem. Rev. 1995, 95, 677-695.

(23) Ledesma, C.; Yang, J.; Chen, D.; Holmen, A. ACS Catal. 2014, 4, 4527-4547.

(24) Van Dijk, H. A. J. The Fischer-Tropsch synthesis A mechanistic study using transient isotopic tracing, Ph.D. Thesis, Eindhoven University of Technology, Eindhoven, 2001.

(25) Govender, N. S. Mechanistic study of the High- Temperature Fischer-Tropsch Synthesis using transient kinetics, Ph.D. Thesis, Eindhoven University of Technology, Eindhoven, 2010.

(26) Fletcher, J. V. Mechanistic Pathways of the High Temperature Fischer-Tropsch Synthesis, Ph.D. Thesis, Eindhoven University of Technology, Eindhoven, 2016.

(27) Ledesma, C.; Yang, J.; Blekkan, E. A.; Holmen, A.; Chen, D. ACS Catal. 2016, 6, 6674-6686.

(28) Lohitharn, N.; Goodwin, J., Jr. J. Catal. 2008, 257, 142-151.

(29) Lohitharn, N.; Goodwin, J. J. Catal. 2008, 260, 7-16.

(30) Yang, J.; Qi, Y.; Zhu, J.; Zhu, Y.-A.; Chen, D.; Holmen, A. J. Catal. 2013, 308, 37-49. 
(31) Den Breejen, J. P.; Radstake, P. B.; Bezemer, G. L.; Bitter, J. H.; Frøseth, V.; Holmen, A.; Jong, K. P. d. J. Am. Chem. Soc. 2009, 131, $7197-7203$.

(32) Yang, J.; Tveten, E. Z.; Chen, D.; Holmen, A. Langmuir 2010, 26, 16558-67.

(33) Yang, J.; Chen, D.; Holmen, A. Catal. Today 2012, 186, 99-108.

(34) Enger, B. C.; Frøseth, V.; Yang, J.; Rytter, E.; Holmen, A. J. Catal. 2013, 297, 187-192.

(35) Winslow, P.; Bell, A. T. J. Catal. 1984, 86, 158-172.

(36) Van Dijk, H. A. J.; Hoebink, J. H. B. J.; Schouten, J. C. Top.

Catal. 2003, 26, 111-119.

(37) Qi, Y.; Yang, J.; Chen, D.; Holmen, A. Catal. Lett. 2015, 145, $145-161$.

(38) De Mongeot, F. B.; Toma, A.; Molle, A.; Lizzit, S.; Petaccia, L.; Baraldi, A. Phys. Rev. Lett. 2006, 97, 056103.

(39) Shetty, S.; Jansen, A. P. J.; van Santen, R. A. J. Am. Chem. Soc. 2009, 131, 12874-12875.

(40) Shetty, S.; van Santen, R. A. Catal. Today 2011, 171, 168-173.

(41) Ge, Q.; Neurock, M. J. Phys. Chem. B 2006, 110, 15368-15380.

(42) Liu, J.-X.; Su, H.-Y.; Li, W.-X. Catal. Today 2013, 215, 36-42.

(43) Hammer, B. Phys. Rev. Lett. 1999, 83, 3681-3684.

(44) Dahl, S.; Logadottir, A.; Egeberg, R. C.; Larsen, J. H.; Chorkendorff, I.; Törnqvist, E.; Nørskov, J. K. Phys. Rev. Lett. 1999, 83, 1814-1817.

(45) Honkala, K.; Hellman, A.; Remediakis, I. N.; Logadottir, A.; Carlsson, A.; Dahl, S.; Christensen, C. H.; Norskov, J. K. Science 2005, $307,555-8$.

(46) Van Hardeveld, R.; Hartog, F. Surf. Sci. 1969, 15, 189-230.

(47) Van Helden, P.; Ciobîcă, I. M.; Coetzer, R. L. J. Catal. Today 2016, 261, 48-59.

(48) Qi, Y.; Yang, J.; Duan, X.; Zhu, Y.-A.; Chen, D.; Holmen, A. Catal. Sci. Technol. 2014, 4, 3534-3543.

(49) Ojeda, M.; Nabar, R.; Nilekar, A. U.; Ishikawa, A.; Mavrikakis, M.; Iglesia, E. J. Catal. 2010, 272, 287-297.

(50) Loveless, B. T.; Buda, C.; Neurock, M.; Iglesia, E. J. Am. Chem. Soc. 2013, 135, 6107-6121.

(51) Tuxen, A.; Carenco, S.; Chintapalli, M.; Chuang, C. H.; Escudero, C.; Pach, E.; Jiang, P.; Borondics, F.; Beberwyck, B.; Alivisatos, A. P.; Thornton, G.; Pong, W. F.; Guo, J.; Perez, R.; Besenbacher, F.; Salmeron, M. J. Am. Chem. Soc. 2013, 135, 2273-8.

(52) Mitchell, W. J.; Xie, J.; Jachimowski, T. A.; Weinberg, W. H. J. Am. Chem. Soc. 1995, 117, 2606-2617.

(53) Chen, W.; Zijlstra, B.; Pestman, R.; Hensen, E. ChemCatChem

2017, DOI: $10.1002 /$ cctc. 201701203 .

(54) Borodziński, A.; Bonarowska, M. Langmuir 1997, 13, 56135620.

(55) Carballo, J. M. G.; Yang, J.; Holmen, A.; García-Rodríguez, S.;

Rojas, S.; Ojeda, M.; Fierro, J. L. G. J. Catal. 2011, 284, 102-108.

(56) Schweicher, J.; Bundhoo, A.; Kruse, N. J. Am. Chem. Soc. 2012, 134, 16135-16138.

(57) Kruse, N.; Schweicher, J.; Bundhoo, A.; Frennet, A.; Visart de Bocarmé, T. Top. Catal. 2008, 48, 145-152.

(58) Schweicher, J.; Bundhoo, A.; Frennet, A.; Kruse, N.; Daly, H.; Meunier, F. C. J. Phys. Chem. C 2010, 114, 2248-2255.

(59) Shetty, S. G.; Ciobica, I. M.; Hensen, E. J.; van Santen, R. A. Chem. Commun. 2011, 47, 9822-4.

(60) Winslow, P.; Bell, A. T. J. Catal. 1985, 94, 385-399.

(61) Toyoshima, I.; Somorjai, G. A. Catal. Rev.: Sci. Eng. 1979, 19, $105-159$.

(62) Cant, N. W.; Bell, A. T. J. Catal. 1982, 73, 257-271.

(63) Ralston, W. T.; Melaet, G.; Saephan, T.; Somorjai, G. A. Angew. Chem., Int. Ed. 2017, 56, 7415-7419.

(64) Nakamura, J.; Tanaka, K.-i.; Toyoshima, I. J. Catal. 1987, 108, $55-62$.

(65) Nakamura, J.; Toyoshima, I.; Tanaka, K.-i. Surf. Sci. 1988, 201, 185-194.

(66) Campbell, C. J. Catal. 2001, 204, 520-524.

(67) Stegelmann, C.; Andreasen, A.; Campbell, C. T. J. Am. Chem. Soc. 2009, 131, 8077-8082.
(68) Filot, I. A. W.; van Santen, R. A.; Hensen, E. J. M. Angew. Chem., Int. Ed. 2014, 53, 12746-12750. 